\title{
Impactos iniciales de la financiación de la educación superior con recursos del presupuesto participativo: evidencia para Medellín'
}

\author{
Initial Impacts of Higher Education Financing with \\ Participatory Budget Resources: Evidence for Medellín
}

\author{
Silvio Fernando López-Mera² \\ Docente investigador de la Universidad de Antioquia y de ESUMER, Medellín, Colombia \\ Especialista de proyecciones de la Alcaldía de Medellín, Colombia \\ Consultor Independiente \\ silvio.lopez@medellin.gov.co \\ ORCID: https://orcid.org/0000 000275770881 \\ David Eduardo Quintero-Rendón ${ }^{3}$ \\ Instructor de desarrollo humano para Comfama, Medellín, Colombia \\ Empresario y fundador de la Corporación "Escuela de Líderes Jaime Garzón”, Medellín, Colombia \\ Consultor independiente con "Piensapiens", Medellín, Colombia \\ davide.quintero@udea.edu.co \\ ORCID: https://orcid.org/0000 000217302529
}

Recibido: 05-06-2018

Aprobado: 20-03-2019

1 Versión modificada del trabajo de grado calificado como "Cum Laude" para optar al título de Maestría en Políticas Públicas en la Universidad de Antioquia.

2 Magister en Políticas Públicas, Magíster en Economía.

3 Magister en Políticas Públicas. 


\title{
Resumen
}

El estudio evalúa el impacto de la financiación de la educación superior en Medellín, con recursos del programa de presupuesto participativo, durante el periodo entre 2007 y 2015. Se estudia el impacto sobre la ocupación, ingresos, tenencia de hijos, estado civil y movilización socioeconómica. Para lo anterior, se emplea la base certificada del Sisbén de 2015 y la base de inscritos al programa. Se aprovecha la regla de elegibilidad del tratamiento, por lo cual se estima un modelo de regresión discontinua nítida. Los resultados indican que la población elegible en el margen presenta características similares a la no elegible y que el programa reduce la probabilidad de ocuparse y por tanto de recibir ingresos, así como la de tener hijos, pero incrementa las posibilidades de movilización socioeconómica y de acceso a la educación superior de la población de escasos recursos. No se evidencia algún efecto en el cambio de estado civil.

Palabras clave: educación; financiación; presupuesto participativo; regresión discontinua; evaluación de impacto.

Clasificación JEL: I2O, I21, I22, I28, H52, C52.

\begin{abstract}
This paper assesses the impact that higher education funding has had in Medellin with resources from the Municipal Administration's participatory budget program during the 2007-2015 period. The impact on employment, income, early children, civil status and improvement of the economic situation in subsequent years to the financing of the program is studied employing the certified database of the Sisben 2015 and the database of people enrolled in the program. The treatment eligibility rule is used, so a sharp discontinuous regression design is estimated; the results indicate that the non-eligible population in the margin show similiar features to those eligible. The program reduces the probability of being employed and receiving an income as well as having children. However, it increases the chances for low-income people to access higher education and achieve a higher socio-economic level. There is no evidence of any effect on marital status.
\end{abstract}

Keywords: Education; Financing; Participatory Budget; RDD; Impact. 


\section{Introducción}

Por más de trece años, las comunidades de las 16 comunas y 5 corregimientos del Municipio de Medellín vienen priorizando los recursos entregados en el marco del Programa de Planeación Local y Presupuesto Participativo (PLyPP) de la Alcaldía, que corresponden al 5\% del presupuesto anualizado del municipio. Estos dineros son empleados con el fin de dar soluciones a importantes problemáticas en salud, infraestructura, seguridad, convivencia, etc. De esta manera, se espera que contribuyan a mejorar de forma gradual el bienestar y calidad de vida de los medellinenses, bajo el supuesto de que en cada territorio existen unas particularidades y problemáticas, necesidades o faltantes, que conllevan a la existencia de una desigualdad espacial cuya solución varía según el territorio.

Por supuesto, entre los destinos de las inversiones realizadas con recursos de PLyPP está el cofinanciamiento de estudios en educación superior, partiendo de la siguiente evidencia empírica: dentro de las diferencias existentes entre los territorios de la ciudad se encuentran el desigual acceso y permanencia en la educación (en todos sus niveles), así como en indicadores de calidad de vida, como alfabetización o nivel educativo más alto alcanzado, entre otros.

En consecuencia, la Administración viene promoviendo la financiación de la educación superior con becas y créditos condonables para mejorar el acceso y permanencia de los jóvenes en el sistema. Sin embargo, a pesar de que el programa se viene implementando desde hace varios años e involucra una gran cantidad de recursos, a la fecha no se ha efectuado una evaluación de impacto de esta estrategia en torno a la educación. He ahí la relevancia del presente trabajo.

Aprovechando que la regla de elegibilidad de los beneficiarios del programa calcula un puntaje, es posible identificar el efecto para la población tratada alrededor del puntaje de corte, a través de la metodología de regresión discontinua en su versión nítida. Se evalúan los efectos locales del programa en las siguientes variables de impacto: ocupación, ingresos individuales y familiares, y condiciones de vida (específicamente, tenencia de hijos, estado civil y cambio de estrato socioeconómico). Esta investigación se constituye como pionera en la ciudad al evaluar el impacto de la financiación de estudios de pregrado con recursos de PLyPP y, en general, de los fondos de financiamiento existentes en Medellín.

Para ello, el presente estudio emplea la base de datos de inscritos al programa para el periodo 20072015 de la Agencia Sapiencia y la base certificada municipal del Sisbén de 2015. Los resultados de las estimaciones sugieren que, en el margen, los individuos son similares y que el programa reduce la probabilidad de que la población beneficiaria se enganche laboralmente y, por tanto, de obtener ingresos. Así mismo, disminuye la posibilidad de embarazo, pero incrementa la probabilidad de acceso al sistema de educación superior y mejora la estratificación socioeconómica en el largo plazo. No se encuentra evidencia de efecto en el estado civil.

El documento se divide en seis secciones. En la primera, se aborda la teoría económica que respalda la construcción de programas de acumulación de capital humano y se presentan algunas evidencias de programas de financiación. En la segunda sección se describe el contexto de la ciudad y su desigualdad intraterritorial-hechos estilizados que dan respuesta a la necesidad de implementar programas de financiamiento educativo- y se describe el programa. En la tercera sección se presentan la metodología y los datos. La siguiente presenta los principales resultados. En la quinta se realiza una discusión y recomendaciones de política. La última sección presenta las conclusiones.

\section{Educación y desarrollo: teoría y evidencia sobre su provisión}

El acceso a la educación es un determinante de las posibilidades futuras de empleos bien remunerados, constituyéndose así en un factor preponderante de movilidad social, desarrollo humano, reducción de la pobreza y desigualdad (López, 2010; López, 2013; Sen, 1999). La educación y el acceso son elementos indispensables para lograr un legítimo desarrollo y una eficiente organización social. 
Basados en la teoría del capital humano, por ejemplo, se argumenta que la educación es determinante de los ingresos presentes y futuros de las personas, al igual que de sus oportunidades y capacidades (Sen, 1999). En ese sentido, se constituye para cada persona y nación en una inversión en donde se calculan sus beneficios y costos (Pantoja, 2010). Adicionalmente, la educación brinda una serie de beneficios sociales (externalidades) que terminan impactando en la sociedad (ver Gráfico 1).

\section{Educación superior y el presupuesto participativo en Colombia y Medellín}

Las diferencias sociales y económicas al interior de las ciudades motivaron a la adopción, por parte de Colombia, de una herramienta de democracia participativa conocida como Presu- puesto Participativo. Dicho proceso surgió a finales de los 80, en algunos municipios de Brasil, como respuesta a los movimientos sociales que se desarrollaron a lo largo de la década anterior, los cuales reclamaban mejores condiciones de vida de la población y control sobre el destino de los recursos públicos. En el país, esta forma de distribución del presupuesto, participativa/ democrática, se viene implementando a partir del 2004 en algunas ciudades como Bogotá D.C., Villavicencio, Envigado, Chía, Ibagué, Pasto y Medellín.

\subsection{El contexto de ciudad}

En Medellín se evidenciaban entre 2004 y 2005 notables diferencias entre sus 16 comunas y 5 corregimientos. El Gráfico 2 registra el Índice de Desarrollo Humano (IDH) para la ciudad en 2004 y 2005, por comuna o corregimiento, a partir de la Encuesta de Calidad de Vida de Medellín.

\begin{tabular}{|c|c|c|}
\hline \multicolumn{3}{|c|}{ Gráfico 1. La educación y sus beneficios } \\
\hline $\begin{array}{l}\text { Beneficios } \\
\text { individuales }\end{array}$ & $\begin{array}{l}\text { * Mayores salarios (ingresos) } \\
\text { * Mejores condiciones de trabajo } \\
\text { * Satisfacción personal y familiar } \\
\text { * Mayores y mejores oportunidades de trabajo } \\
\text { * Prestigio laboral y profesional } \\
\text { * Mejor salud } \\
\text { * Desarrollo individual } \\
\text { * Expansión de capacidades individuales }\end{array}$ & $\begin{array}{l}\text { (Sen, 1999; Dynarski, 2000; Kug, 2002; Kane, 2003; } \\
\text { Lemieux y Milligan, 2004; Tomasecski, 2004; Correa, } \\
\text { 2005; London y Formishella, 2006; Contreras y } \\
\text { Cuevas, 2009; Ospina y Gimenez, 2009; López, 2010; } \\
\text { Pantoja, 2010; Cañada, 2011; Deming, 2011; Gurgand, } \\
\text { Lorenceau y Melonio, 2011; López, 2003; Melo, } \\
\text { Hernández y Ramos, 2014; Sánchez, 2014; Velasco, } \\
\text { 2014; Acosta, Osorno y Rodríguez, 2016; Freire y } \\
\text { Tejeiro, 2016; Martínez, 2016). }\end{array}$ \\
\hline Externalidades & \multicolumn{2}{|c|}{$\begin{array}{l}\text { * Reducción de actividades socialmente no deseables (ej. Delincuencia) (Deming, 2011). } \\
\text { * Uso alternativo (productivo) del tiempo libre (Deming, 2011). } \\
\text { * Competitividad y productividad (Márquez, s. f.; Sen, 1999). } \\
\text { * Desarrollo científico y tecnológico (Márquez, s. f.; Sen, 1999). } \\
\text { * Población saludable (London y Formishella, 2006). }\end{array}$} \\
\hline Impactos & \multicolumn{2}{|c|}{$\begin{array}{l}\text { * Crecimiento económico (Márquez, s. f.; Sen, 1999). } \\
\text { * Movilidad social, desarrollo humano, reducción de la pobreza y desigualdad (López, 2010; López, } \\
\text { 2013; Sen, 1999). } \\
\text { * Cohesión y progreso social (Márquez, s. f.; Sen, 1999). } \\
\text { * Fortalecimiento institucional de las naciones (North, 1990). } \\
\text { * Goce de los derechos y cumplimiento de deberes (Tomasevski, 2004). } \\
\text { * Mitigación de las desigualdades y probreza (CEPAL, 2017; London y Formishella, 2006; López, 2010; } \\
\text { López, 2013; Sen, 1999). } \\
\text { * Desarrollo sostenible y mejoramiento de la sociedad como un todo (Unesco, 1998, en Ruth, 2010). }\end{array}$} \\
\hline
\end{tabular}

Fuente: elaboración propia. 


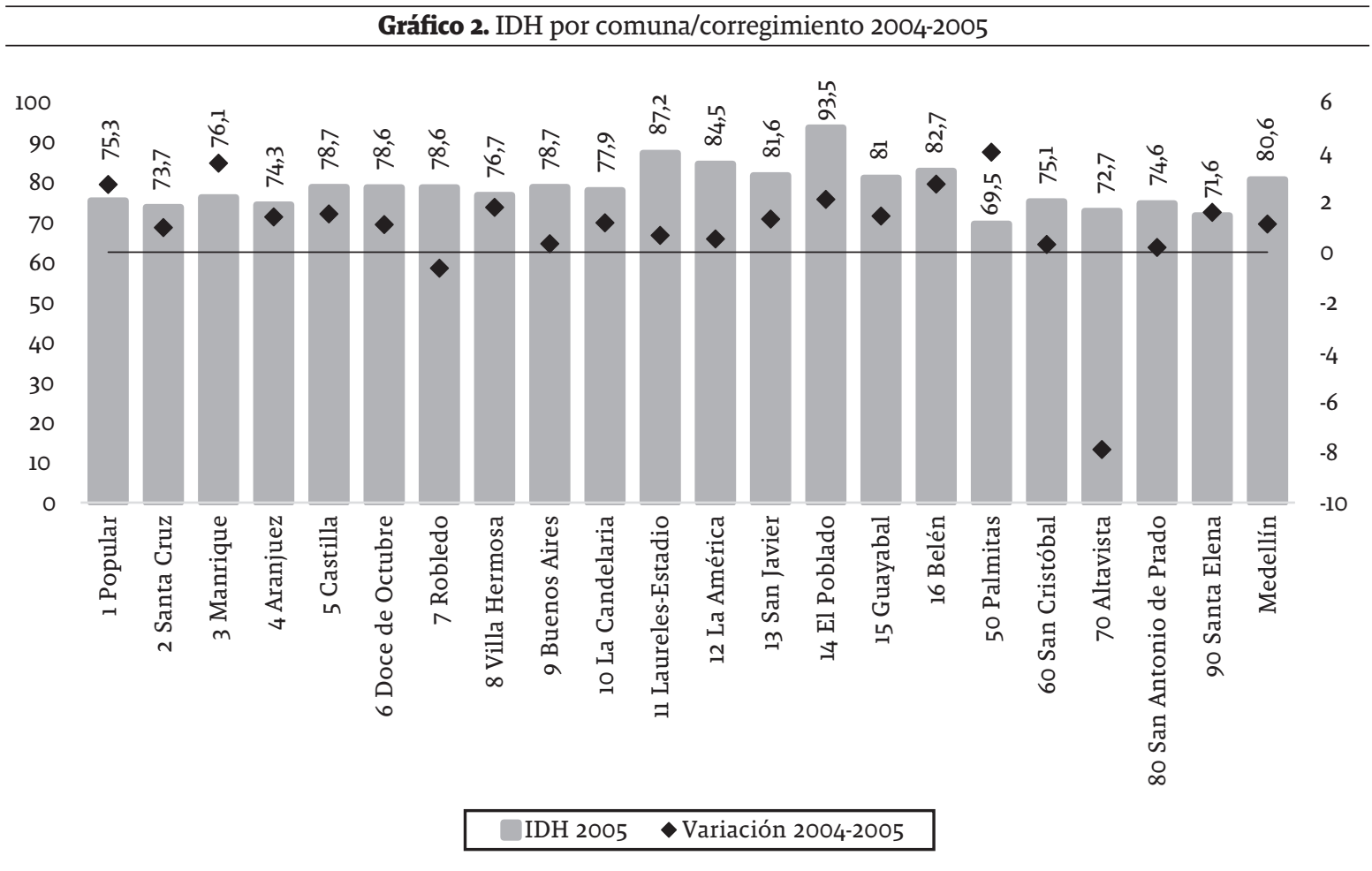

Fuente: ECV (2004, 2005).

En el ámbito educativo la situación es similar, especialmente en el nivel de básica secundaria, media y mucho más en superior. La tasa de matrícula, por ejemplo, es reflejo de considerables diferencias entre territorios de un mismo municipio (ver Gráfico 3).

Si bien las evidencias que arrojan estos indicadores sugieren que en su agregado -y para el caso puntual de algunos territorios- la ciudad ha mejorado, se siguen encontrando marcadas diferencias entre sus territorios. Lo anterior indica entonces una evidente desigualdad al interior de la ciudad: "Entre el periodo de 1996 y 2006 se registra un crecimiento en la desigualdad en Medellín al concentrarse los ingresos en algunos sectores minoritarios" (Bernal, 2006, citado por Aguirre, 2010, p. 93). Son precisamente estas diferencias considerables entre territorios las que motivaron a implementar PLyPP particularmente en Medellín, con el fin de cerrar las brechas territoriales y mejorar así las condiciones de vida en el agregado.
¿Pero por qué facilitar el acceso y permanencia a través del otorgamiento de auxilios económicos? Dado que PLyPP es una inversión por territorio de la ciudad, no era viable subsidiar a la oferta debido a que las Instituciones de Educación Superior (IES) prestan el servicio educativo a toda la ciudad e incluso a toda la región y el país, y entregar por tanto recursos a las IES no era una medida eficaz para reducir las desigualdades territoriales, pues el recurso terminaría siendo un servicio potencialmente no excluyente. Se debía escoger, subsidiar a la demanda y, específicamente, a los jóvenes de bajos recursos según su residencia.

Lo anterior es apoyado con los resultados de un estudio que contrata anualmente la Secretaría de Educación de Medellín -SEM- (2017) con el cual se encontró que menos de la mitad de los bachilleres de colegios públicos continúan en el sistema educativo, ya sea en programas tecnológicos o profesionales (ver Gráfico 4). 


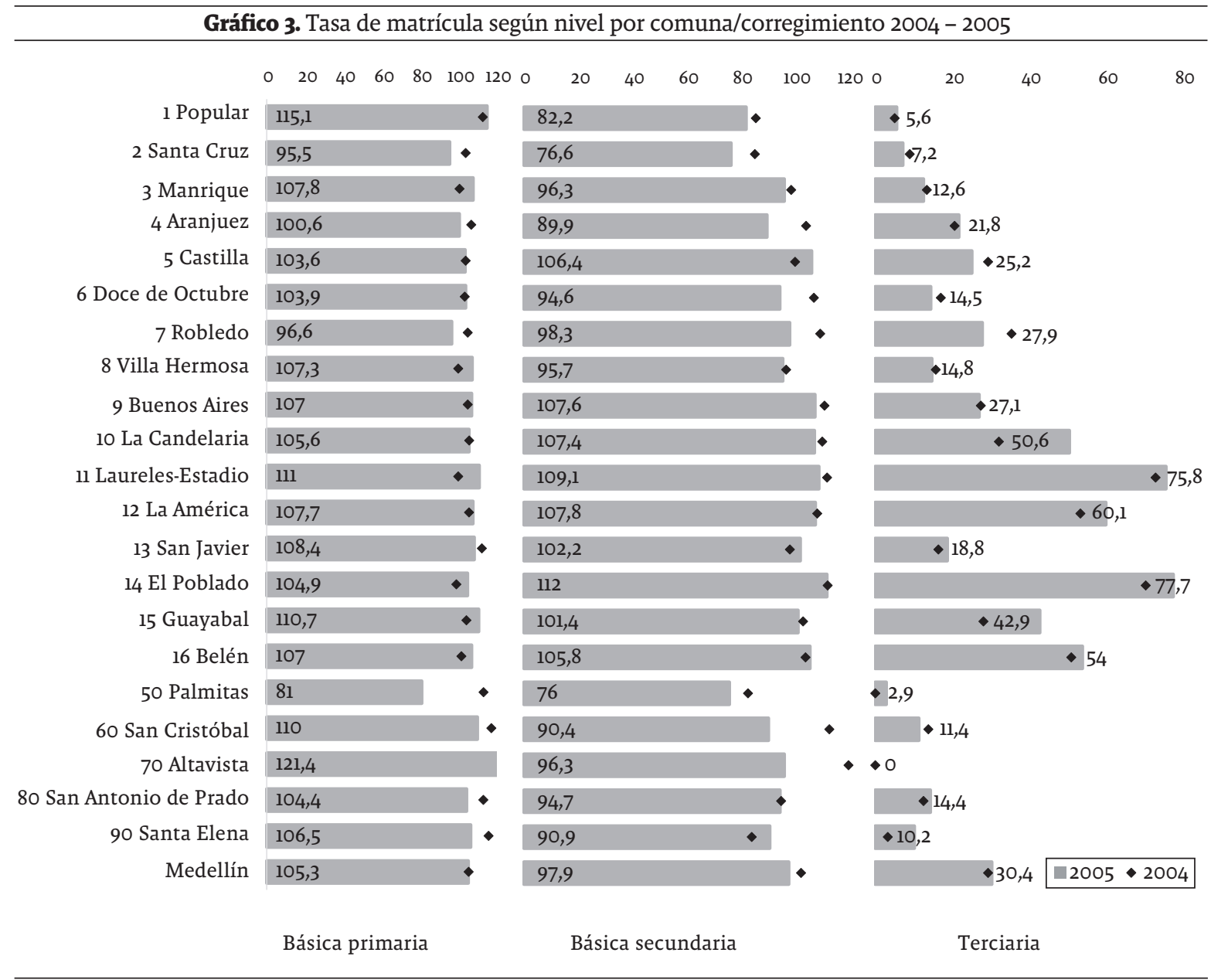

Fuente: $\operatorname{ECV}(2004,2005)$.

\subsection{Acerca del programa}

La Administración anualmente destina un $5 \%$ del presupuesto para que cada uno de los 21 territorios ${ }^{4}$ que conforman la ciudad prioricen iniciativas sociales mediante votaciones en cada territorio, donde los ciudadanos eligen los proyectos que consideran como prioritaria su ejecución en el año siguiente para resolver alguna necesidad o problemática particular de la comuna o corregimiento. Los proyectos que

4 La distribución de ese presupuesto del $5 \%$ en los 21 territorios se basa en el tamaño de la población y del Índice Multidimensional de Calidad de Vida (IMCV), de tal forma que a mayor población y menor IMCV se le asigna mayor presupuesto. Para más detalles de la operación de PLyPP puede acudirse al Decreto 0697-2017. en cada territorio tengan el mayor número de votos y puedan financiarse completamente con el recurso asignado por la Alcaldía, son priorizados y ejecutados en la siguiente vigencia por el operador/contratista que la Administración haya puesto en consideración. Dentro de los proyectos a votación, ha estado año a año la financiación de estudios superiores. Es así como entre el 2005 y 2016 se han beneficiado más de seis mil jóvenes (ver Gráfico 5). Con respecto al presupuesto focalizado, se han invertido más de noventa mil millones de pesos (ver Gráfico 6).

A los seleccionados por el programa se les financia la matrícula y/o el sostenimiento, hasta por un total de cuatro salarios mínimos mensuales legales vigentes, cada semestre, durante cada 


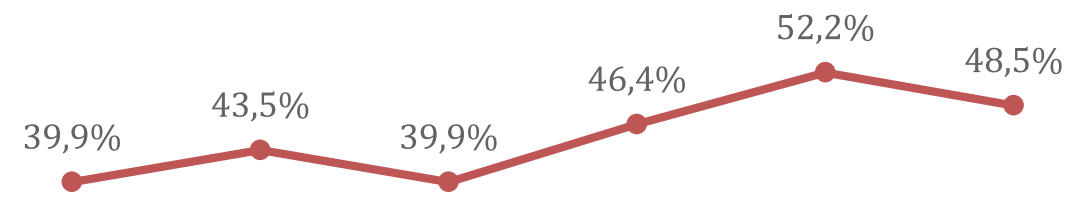

$\begin{array}{lllll}2011 & 2012 & 2013 & 2014 & 2015\end{array}$

Fuente: informe de resultados, Secretaría de Educación de Medellín (2017).

uno de los semestres que dura el programa o que le falta por terminar. ${ }^{5}$

Para acceder al programa, el aspirante debe cumplir con los siguientes requisitos:

- Haber nacido en Medellín o llevar domiciliado mínimo los últimos cinco años.

- Llevar mínimo dos años de domicilio en la comuna/corregimiento.

- Estar en proceso de admisión, ser admitido o estar estudiando en una institución de educación superior (IES) en la ciudad.

- Haber presentado pruebas Saber 11.

- No poseer título universitario, excepto si es por modalidad de ciclos.

Cumpliéndolos, el proceso de selección que sigue implica el cálculo de un puntaje individual por parte de Sapiencia, el cual considera las siguientes variables que afectan el puntaje de manera positiva o negativa, dependiendo de si constituyen una mayor o menor desventaja, respectivamente, tal y como lo refleja el paréntesis (ver Anexo 1):

- Estrato socioeconómico del hogar de residencia (-).

- Sector del colegio de donde se graduó (públi$\mathrm{CO}+$ ).

- Resultados en Pruebas Saber 11 (+).

- Tiempo de rezago entre el año de inscripción y el de grado $11^{\circ}(-)$.

- Nivel de formación de pregrado deseado (tecnológico +).

- Naturaleza de la IES a la cual aspira ingresar (pública +).

- Puntaje del Sisbén (-).

\section{Datos y metodología}

\section{a. Fuentes de información}

Con el fin de estudiar el efecto de la financiación de la educación superior con recursos de PLyPP se utilizaron dos fuentes de información:

5 Este programa de financiamiento se conoció al inicio como Fondo Camino a la Educación Superior, ahora se denomina Fondo Pregrado Sapiencia con recursos de Presupuesto Participativo. 


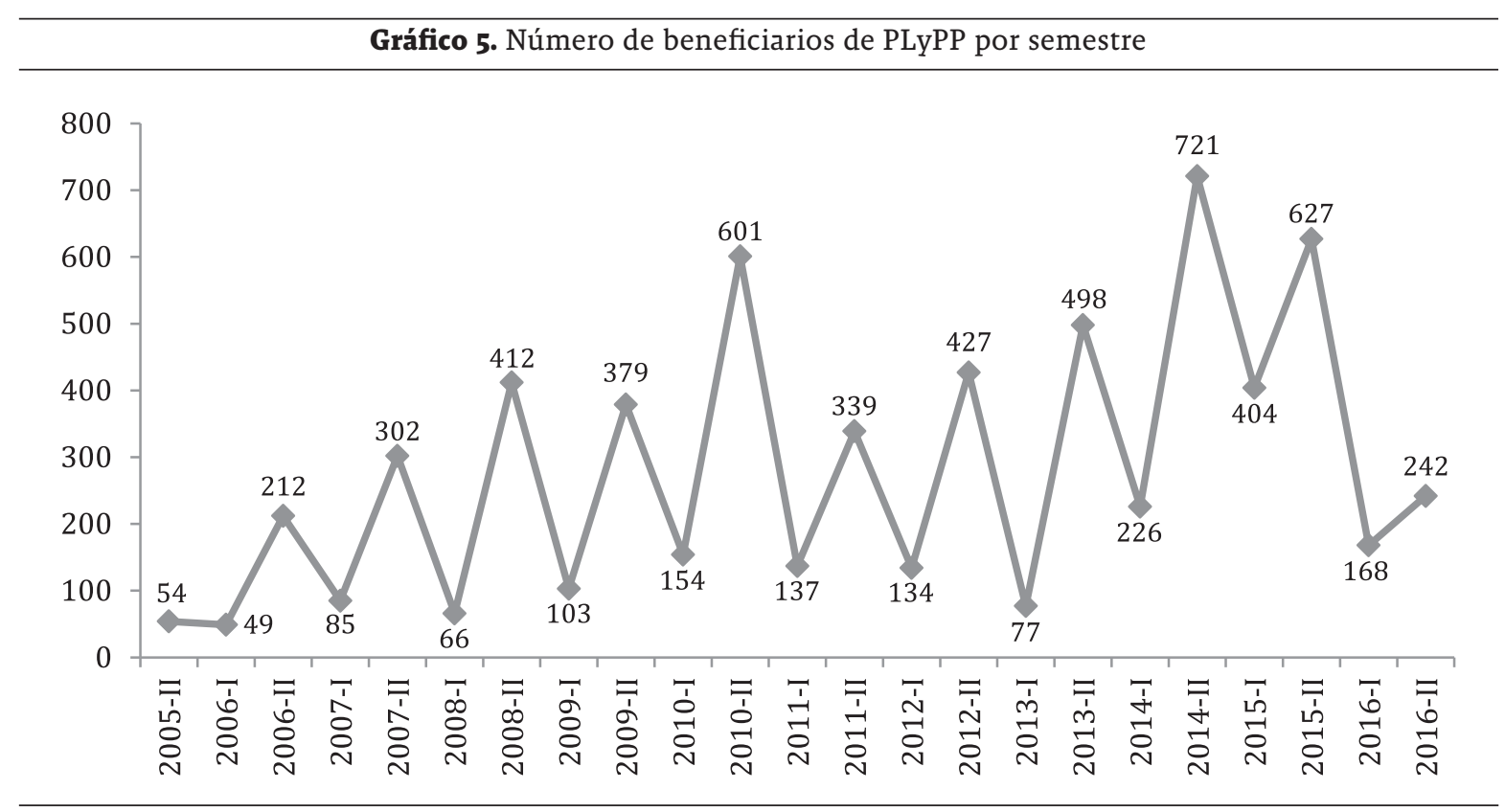

Fuente: Sapiencia (2017).

Gráfico 6. Recursos invertidos en PLyPP 2005-2016 (\$ en millones de pesos)

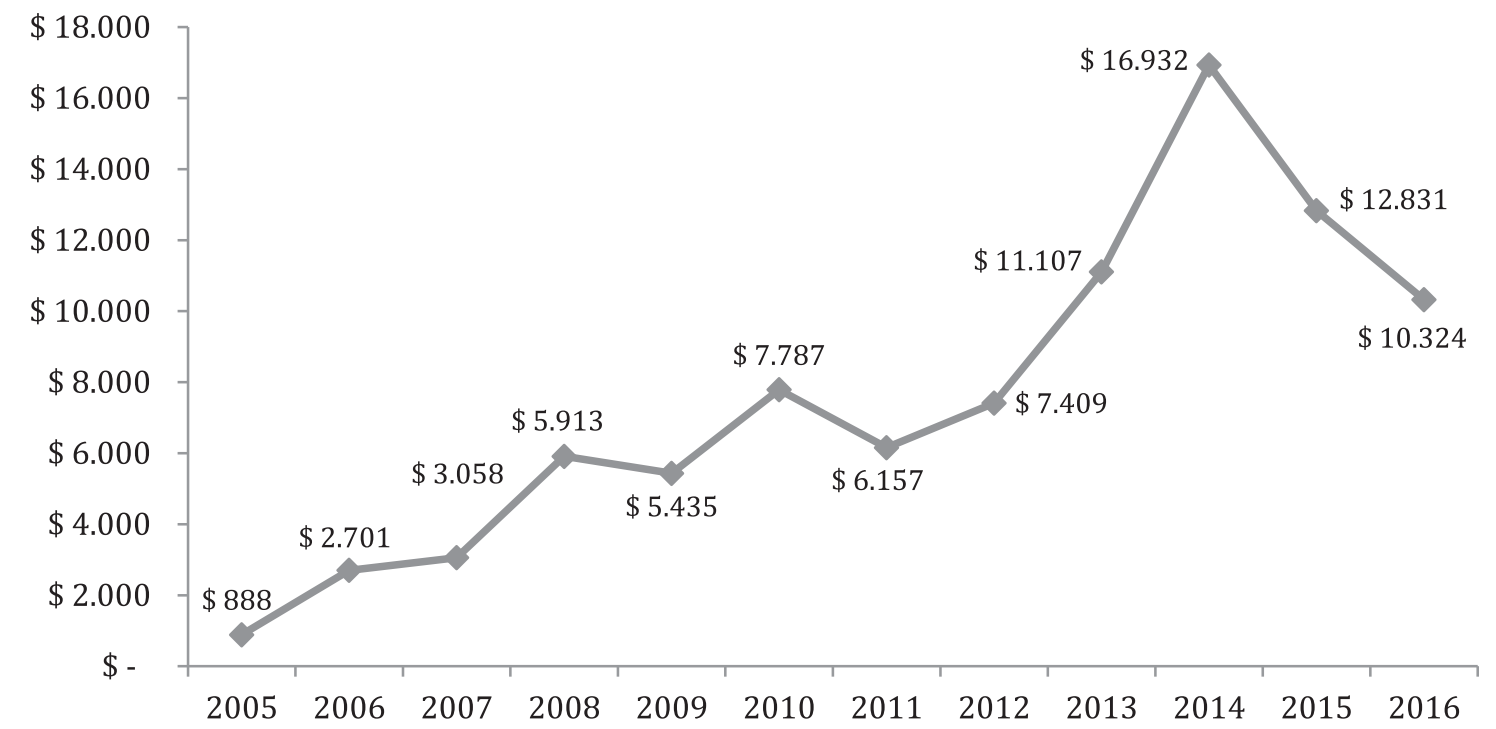

Fuente: Sapiencia (2017). 


\section{Inscritos al Programa}

Se usaron datos de Sapiencia ${ }^{6}$ con información de las personas que se inscribieron en cada convocatoria. En total se tienen 21.615 inscripciones entre el 2007:II y 2015:I (excluyendo el 2008:I, no disponible). Luego de un proceso de depuración, se tienen al final 16.687 registros. La distribución de la población inscrita a PLyPP se sintetiza en el Gráfico 7. Conviene para examinar el comportamiento de las convocatorias en el tiempo y el sexo del aspirante con el fin de identificar si existen diferencias importantes en la misma. Se identifica que, para todas las convocatorias, se han presentado más mujeres que hombres (feminización de la educación: Correa, 2005) y que, en los últimos periodos, las inscripciones aumentaron.

\section{Base certificada Sisbén 2015}

Se emplea la base del Sisbén ${ }^{7}$ versión III de 2015 a nivel de Medellín como base de seguimiento. Tiene 1.869.369 registros con lo cual se obtienen características demográficas de interés.

\section{b. Metodología}

Para estimar el impacto del uso del presupuesto participativo en la financiación de la educación superior en indicadores de educación, estado civil, embarazo y mercado laboral se utiliza la metodología de regresión discontinua (RD). Dicha metodología parte de la existencia de un puntaje exógeno que define la elegibilidad para recibir el tratamiento, esta es denominada como variable de asignación, elegibilidad o también como running variable.

6 Es la Agencia de Educación Superior de Medellín, entidad descentralizada de la Alcaldía creada en el 2013 y encargada de administrar los distintos fondos (becas y créditos) de financiamiento de la educación tanto a nivel de pregrado como a nivel de posgrado y cuyo presupuesto es municipal.

7 Es el Sistema de Identificación de Potenciales Beneficiarios de Programas Sociales que, a través de un puntaje calculado a partir de una encuesta a todo el hogar, clasifica a la población del país de acuerdo con sus condiciones socioeconómicas. A 2015 el porcentaje de la población de la ciudad incluida en el Censo del Sisbén es alrededor del $75 \%$.

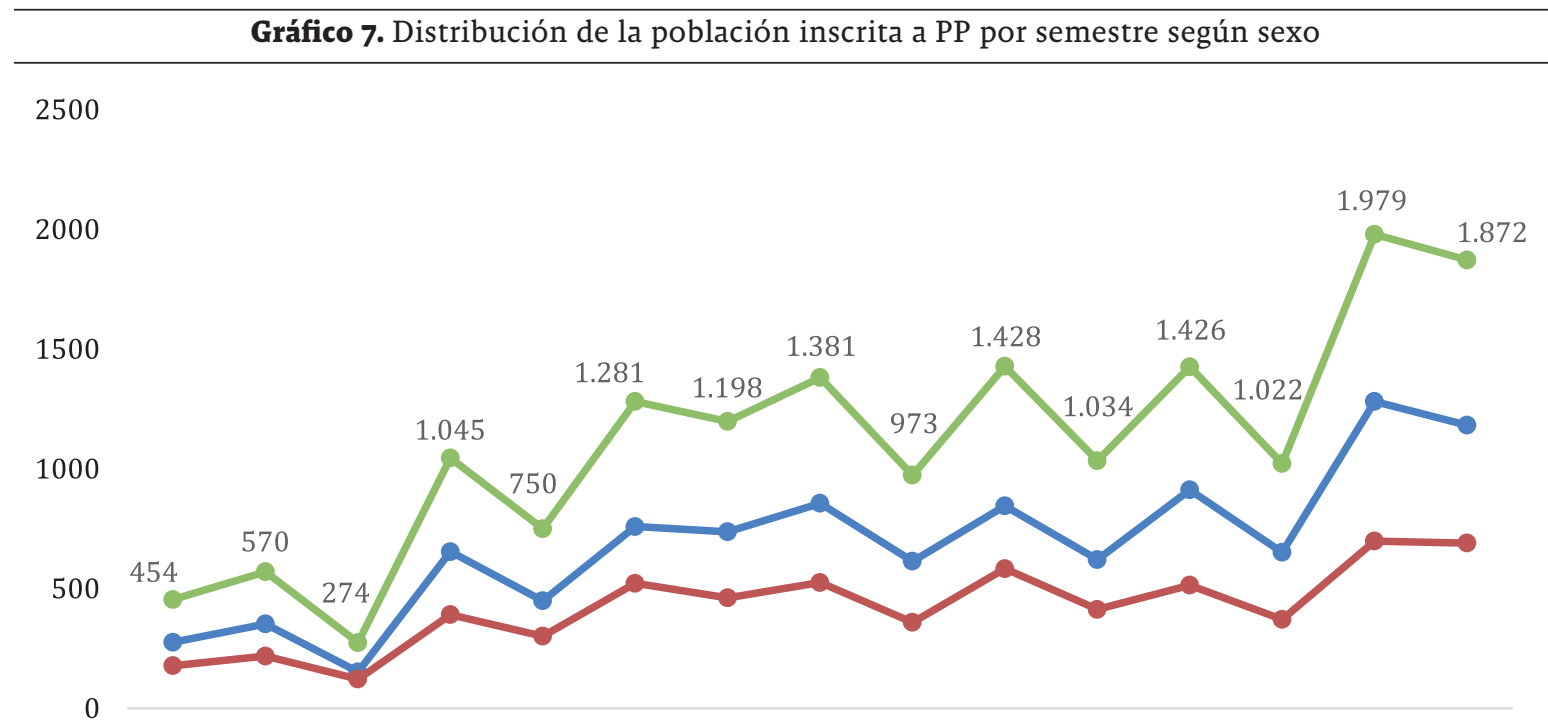

2007:II 2008:II 2009:I 2009:II 2010:I 2010:II 2011:I 2011:II 2012:I 2012:II 2013:I 2013:II 2014:I 2014:II 2015:I

$\longrightarrow$ Mujeres $\longrightarrow$ Hombres $\longrightarrow$ Total*

Fuente: elaboración propia, base de inscritos. 
El tratamiento es asignado con base en una variable que es calculada por los administradores del programa a partir de un conjunto de variables sociodemográficas (descritas más abajo). Si dicho puntaje -la variable de asignación- se ubica en un lado del umbral, la persona es asignada al grupo de tratamiento (a la derecha). Si la variable se ubica del otro lado del corte/umbral, la persona es asignada al grupo control.

La metodología considera que las observaciones alrededor del puntaje de corte son muy similares entre sí. La única diferencia está relacionada con su condición de elegibilidad (Lee y Lemieux, 2010). De esta manera, cualquier diferencia en indicadores posteriores al tratamiento entre personas ubicadas a lado y lado del umbral de elegibilidad será atribuida al programa (Peña y Bernal, 2011).

El efecto del tratamiento se estima sobre:8

- La probabilidad de ocuparse en el mercado laboral (+).

- Recepción y nivel de ingresos individuales y familiares (+).

- Tenencia temprana de hijos (-).

- Cambio en el estado civil distinto a soltero -o pérdida de soltería- (-).

- Cambio en el estrato socioeconómico del hogar (+).

Con respecto a la probabilidad de ocuparse se espera que, gracias a la acumulación de capital humano y mayor cualificación que conlleva la elegibilidad del programa, se incremente (aunque esto en el largo plazo). Debido a que este outcome se obtiene a partir de la base del Sisbén en la cual se encuentran la población informal y formal, la ocupación relacionada es total, dado que no es posible discriminar su situación de formalidad o informalidad. En esta misma lógica de relación estaría el efecto sobre los ingresos. La evidencia al respecto de

8 Entre paréntesis está el efecto que debería tener el programa sobre las variables de impacto de interés. estas dos relaciones es abundante (Acosta, Osorno y Rodríguez, 2016; Iriondo, 2016; Freire, Oliveira y Teijeiro, 2016; Martínez, 2016; Sánchez y Velasco, 2014; Monteiro, Almeida y García, 2014; Cañada, 2011; Solís; 2011; Pantoja, 2010; Dynarski, 2000). Con respecto a la tenencia temprana de hijos y pérdida de soltería se espera que, debido a la ocupación o dedicación al estudio, los beneficiarios presenten menores tasas de fecundidad y cambios en su estado civil de nacimiento. Finalmente, y asumiendo que existe una relación directa entre estrato socioeconómico y calidad de vida u oportunidades, es de esperar que un programa de financiamiento de la educación contribuya a la movilización social y económica.

En este sentido, los indicadores analizados sobre el mercado laboral son: (i) si la persona está trabajando formal o informalmente según su respuesta en la encuesta del Sisbén; 9 (ii) los ingresos totales corrientes mensuales. Estos mismos ingresos pero para los ocupados, ${ }^{10}$ e ingresos corrientes familiares per cápita; y iii) si percibe algún ingreso mensualmente. ${ }^{.1}$ En condiciones de vida las variables de impacto a evaluar son: (iv) si la persona ha mejorado de estrato socioeconómico ${ }^{12}$; (v) si la persona ha estado en embarazo o ha tenido

9 El valor de 1 en este indicador corresponde a que figura como trabajador en el formulario del Sisbén. 0 es otra condición.

10 Los ingresos son mensuales y los disponibles en el Sisbén son totales, lo que agrega los laborales y no laborales (como arriendos, intereses, etc.). Aquí no se realiza algún ajuste por subdeclaración u omisión de ingresos.

11 Es una variable binaria cuya pregunta base en el Sisbén es: "¿Percibe ingresos (laborales, arriendos, subsidios, transferencias, en especie)?". Se considera que el beneficio de la cofinanciación de la matrícula o sostenimiento que reciben los elegibles no lo incluyen como ingreso $y$, por lo tanto, no se reporta dentro de la respuesta de ingresos en el Sisbén.

12 Aquí el cambio en el estrato puede ser producto de una migración o desplazamiento a otro hogar con distinto estrato o a actualizaciones de estrato socioeconómico que el DANE realiza a determinados barrios o zonas de la ciudad. Esto último se presupone que es poco presentado. 
un hijo para el caso de las mujeres ${ }^{13}$; y (vi) si la persona en algún momento ha tenido un estado civil distinto al que por defecto es el de nacimiento (soltería) ${ }^{14}$.

La comparación sobre estos resultados de interés -que registran las personas con un puntaje inmediatamente a la izquierda del punto de corte para cada comuna/corregimiento y año, y aquellos con un puntaje inmediatamente a la derecha de ese mismo corte- brinda evidencia de la relación causal del programa PLyPP sobre esos resultados. Lo anterior bajo el supuesto de que las personas cuyo puntaje los ubica cercanamente a cada lado del corte tienen características muy similares; solo los diferencia el hecho de que aquellos inmediatamente a la derecha son beneficiarios y aquellos inmediatamente a la izquierda no lo son (pues tienen un puntaje inferior al del corte). En el Gráfico $8^{15}$ se muestra esta situación empleando el puntaje normalizado, lo cual permite representar a todas las observaciones independientemente del año/ semestre y comuna/corregimiento. El puntaje normalizado se puede entender como la distancia al punto de corte.

La discontinuidad que se presenta en la probabilidad de ser beneficiario del programa alrededor del puntaje de corte es una condición necesaria para la estimación de la regresión discontinua, que en este caso es sharp (nítida). Esta versión del $\mathrm{RD}$ se emplea con la condición de que el tratamiento sea función determinística y discontinua del puntaje del aspirante (Lemieux y Milligan, 2004). Esto es, que la discontinuidad determina precisamente el tratamiento, por lo que la probabilidad cambia discreta y necesariamente de o a 1 (tal como se observa en el Gráfico 8). La otra posibilidad que hay cuando se traba-

13 La pregunta del formulario del Sisbén es: “¿Está embarazada o ha tenido hijos?". Esta pregunta se aplica exclusivamente a las mujeres, por lo que no considera a los aspirantes hombres.

14 En este caso, el indicador sería l si su estado civil es distinto al de soltero.

15 Puntaje normalizado se calcula como la diferencia entre el puntaje del aspirante y el puntaje de corte según comuna/corregimiento y año. ja con RD es la fuzzy (borrosa) en la que con la discontinuidad se determina quién es elegible y quién no, pero no de manera determinista, sino aleatoria.

Con cualquiera de las dos versiones del RD, dado que con esta metodología el efecto del tratamiento es estimado en la discontinuidad, se tienen menos observaciones por lo que es viable la pérdida de potencia estadística. No obstante, el RD produce una estimación válida (no sesgada) del efecto del tratamiento en la discontinuidad alrededor del corte y se constituye como una forma útil para evaluar políticas públicas. ${ }^{16} \mathrm{La}$ única limitación importante aquí es que las conclusiones solamente se aplican a observaciones alrededor del corte (no se sabría el impacto en aquellos que están lejos del umbral). Se habla de impacto bajo esta metodología cuando corresponde al efecto local (Pomeranz, 2011).

Luego, como el tratamiento de interés es función determinística y discontinua del puntaje $P_{i}$ obtenido por el aspirante, bajo la regresión discontinua nítida (sharp $R D$ ) se tiene la siguiente variable indicadora de elegibilidad $D_{i}$ :

$D_{i}=\left\{\begin{array}{l}1 \text { si } P_{i} \geq P_{\mathrm{o}} \\ 0 \text { si } P_{i}<P_{\mathrm{O}}\end{array}\right.$

Donde $P_{0}$ corresponde al puntaje de corte. Aquí conviene aclarar que este puntaje es definido por Sapiencia, que es variable semestre a semestre y por comuna/corregimiento. Así mismo, que está determinado por el número de inscritos en cada convocatoria y por el monto del presupuesto participativo focalizado para educación superior, que la junta de acción comunal de cada territorio ha asignado para cada vigencia. Ahora, empleando el puntaje normalizado que se reporta en los gráficos, a continuación, la ecuación (1) quedaría de la siguiente forma:

16 Los parámetros estimados por el método de RD poseen la mayor validez interna entre los estimadores cuasi experimentales (Lee, 2008). 
Gráfico 8. Participación en PLyPP según puntaje normalizado

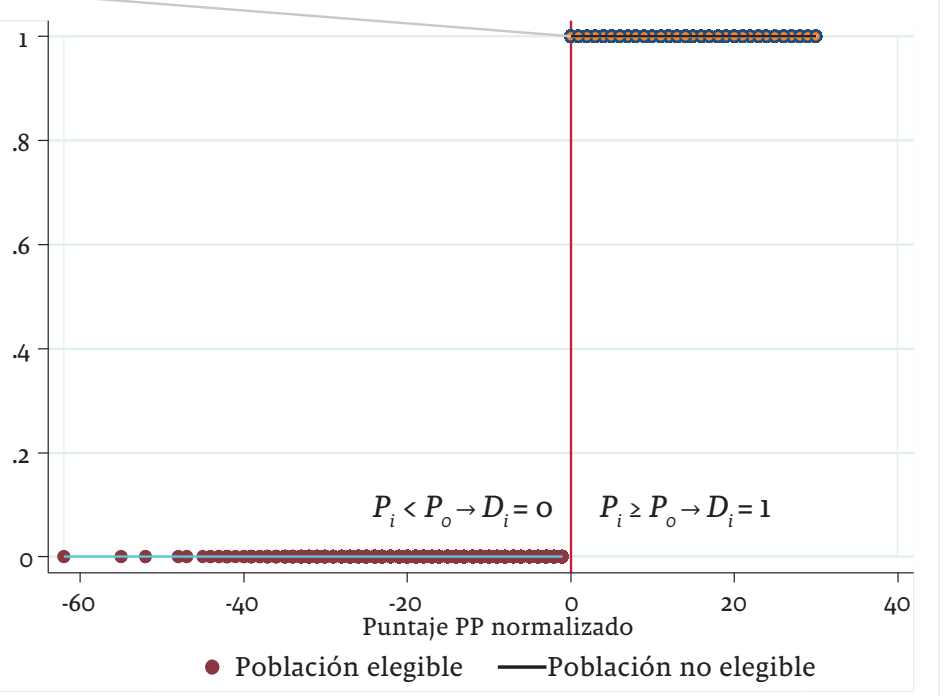

Fuente: elaboración de los autores con base en la información de inscritos PLyPP.

$D_{i}= \begin{cases}1 & \text { si } P_{i}-P_{0} \geq 0 \\ 0 & \text { si } P_{i}-P_{0}<0\end{cases}$

En este caso, el modelo a estimar por MCO con errores estándares robustos es lineal de la siguiente forma: ${ }^{17}$

$$
Y_{i}=\alpha+\beta X_{i}+\delta P N_{i}+\Delta D_{i}+\sum_{c=1}^{C} \rho_{c} C+\varepsilon_{i}
$$

En la ecuación (3), $Y_{i}$ es la variable de impacto para cada individuo $i$. En los casos en que la variable $Y$ es dicotómica (ocupado, cambio de estrato, estado civil, recepción de ingresos y tenencia de hijos) ${ }^{18}$, la ecuación se convierte en un modelo de probabilidad lineal: $X_{i}$ es el vector de covariables compuesto por la edad y sexo de la

17 Toda la programación se realiza en el software Stata.

18 Ocupado toma el valor de 1 si el aspirante es ocupado; cambio de estrato toma el valor de 1 si mejoró (aumentó) de estrato socioeconómico; estado civil toma el valor de 1 si es diferente a soltería; recepción de ingresos toma el valor de 1 si manifiesta que percibe ingresos mensuales; y tenencia temprana de hijos toma el valor de 1 si la aspirante responde "Sí" a la pregunta ¿se encuentra en embarazo o ha tenido hijos? persona; $P N_{i}$ es el puntaje o variable de selección normalizada; mientras que $D_{i}$ es la dummy indicadora de si el individuo $i$ es tratado (igual a l) o no; teniendo presente que los individuos seleccionados para las regresiones corresponden a los que están ubicados hasta 10 puntos alrededor del puntaje de corte (a la izquierda y a la derecha) ${ }^{19}$ según la comuna/corregimiento a la que pertenecen y el año. Adicionalmente se incluyen efectos fijos de territorio $(C)^{20}$, con el fin de capturar las características constantes en el tiempo que son comunes en los inscritos de una misma comuna/corregimiento, pero que pueden diferir a las de otro territorio. ${ }^{21} \varepsilon_{i}$ es el

19 Con el fin de hacer comparaciones y validaciones se tomaron seis rangos alrededor del punto de corte $X_{0}(-10 \mathrm{y}$ $10,-5$ y $5,-4$ y $4,-3$ y $3,-2$ y $2,-1$ y 1 ), por lo que la sub-muestra para cada regresión se reduce a medida que se acorta el rango.

20 Por ejemplo, acceso a servicios públicos domiciliarios, número de bibliotecas o determinados amenities.

21 Aquí conviene mencionar que en la medida en que las características de los inscritos estén balanceadas a ambos lados del corte, el único efecto de incluir las variables de control y de los efectos fijos de territorio en la estimación es reducir los errores estándar de la misma, por lo que al final se tendrían estimadores consistentes. 
término de error que absorbe todo lo que no es explicado por el resto de variables explicativas. Finalmente, $\Delta$ es el coeficiente de medición del impacto. Esto es porque en el valor esperado de diferencia, en la ecuación (3), se cancelan todos los términos excepto $\Delta$ :

$E\left[Y_{i}\left(D_{i}=1\right)-Y_{i}\left(D_{i}=0\right) \mid P_{i}=P_{0}\right]=\Delta$

Para el interés del presente estudio, $\Delta$ corresponde al efecto local promedio del tratamiento $(L A T E)^{22}$, el cual es sólo representativo para los individuos en la vecindad del corte.

Ahora bien, si se evidencia que se requieren términos no lineales de la running variable como un componente cuadrático, por ejemplo, la ecuación (3) quedaría así:

$Y_{i}=\alpha+\beta X_{i}+\delta_{1} P N_{i}+\delta_{2} P N_{i}^{2}+\Delta D_{i}+\sum_{c=1}^{C} \rho_{c} C+\varepsilon_{i}$

Y si, adicionalmente, se identifica un cambio de pendiente antes y luego del umbral, lo que indica que el efecto del tratamiento varía con el puntaje o variable de elegibilidad, es preciso incorporarles a las ecuaciones (3) y (5) una interacción entre la variable de elegibilidad y la dummy del tratamiento, quedando de la forma:

$$
\begin{aligned}
& Y_{i}=\alpha+\beta X_{i}+\delta P N_{i}+\Delta D_{i}+\pi D_{i} P N_{i}+\sum_{c=1}^{C} \rho_{c} C+\varepsilon_{i} \\
& Y_{i}=\alpha+\beta X_{i}+\delta_{1} P N_{i}+\delta_{2} P N_{i}^{2}+\Delta D_{i}+\pi_{1} D_{i} P N_{i}+\pi_{2} D_{i} P N_{i}^{2}+\sum_{c=1}^{C} \rho_{c} C+\varepsilon_{i}
\end{aligned}
$$

La metodología implica suponer la continuidad en las funciones de regresión condicional, esto es: $E[Y(0) \mid P=p]$ y $E[Y(1) \mid P=p]$ sean continuas en $p$ alrededor de $P_{i}=P_{0}$.

Adicionalmente a la discontinuidad en la probabilidad de ser beneficiario del programa en el punto de corte, la metodología requiere que las poblaciones a ambos lados del corte no registren una discontinuidad. Esto es, que las características iniciales demográficas cambien de manera continua en el punto de corte. Básicamente, la elegibilidad de estos aspirantes (los que están cerca al corte) es producto del azar y no de sus características propias.

Esta condición se prueba estimando una ecuación lineal por mínimos cuadrados para cada variable de control en función de la variable de tratamiento $(D)$ y para diferentes tamaños de muestra alrededor del puntaje de corte. En estas regresiones también se incluyeron efectos fijos de comuna/ corregimiento. En este sentido, las ecuaciones siguen la forma funcional:

$X_{i}=\theta+\tau P N_{i}+\gamma D_{i}+\sigma P N_{i} D_{i}+\sum_{c=1}^{C} \vartheta_{C} C+\mu_{i}$

Donde las variables a la derecha ya fueron definidas y $\mu_{i}$ corresponde al término de error. Estas regresiones se muestran en el Anexo 2, mientras que las pruebas gráficas de continuidad para el conjunto de covariables seleccionadas, según la disponibilidad de la información, se sintetizan en el Gráfico 9: en el eje horizontal se ubica el puntaje normalizado (ubicando el puntaje de corte en cero) y en el vertical, el valor de la covariable.

Una dificultad importante aquí fue la disponibilidad de variables para controlar, pues muchas que

22 Por sus siglas en inglés: effect of the local average treatment estimator. El estimador LATE fue propuesto por Imbens y Angrist (1994) para identificar el impacto del tratamiento ante cambios locales. 
Silvio Fernando López-Mera • David Eduardo Quintero-Rendón

Gráfico 9. Gráficas de continuidad en características
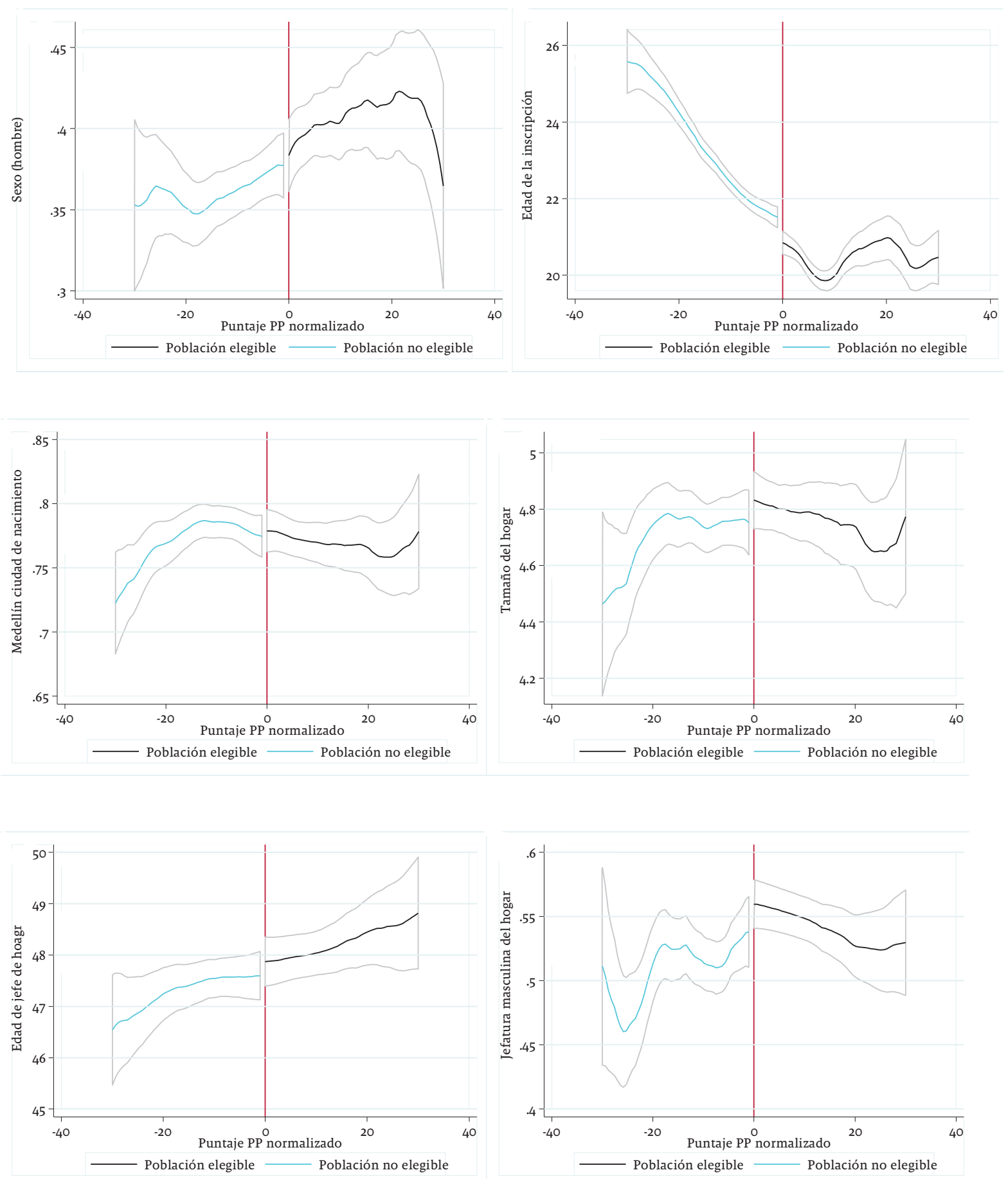

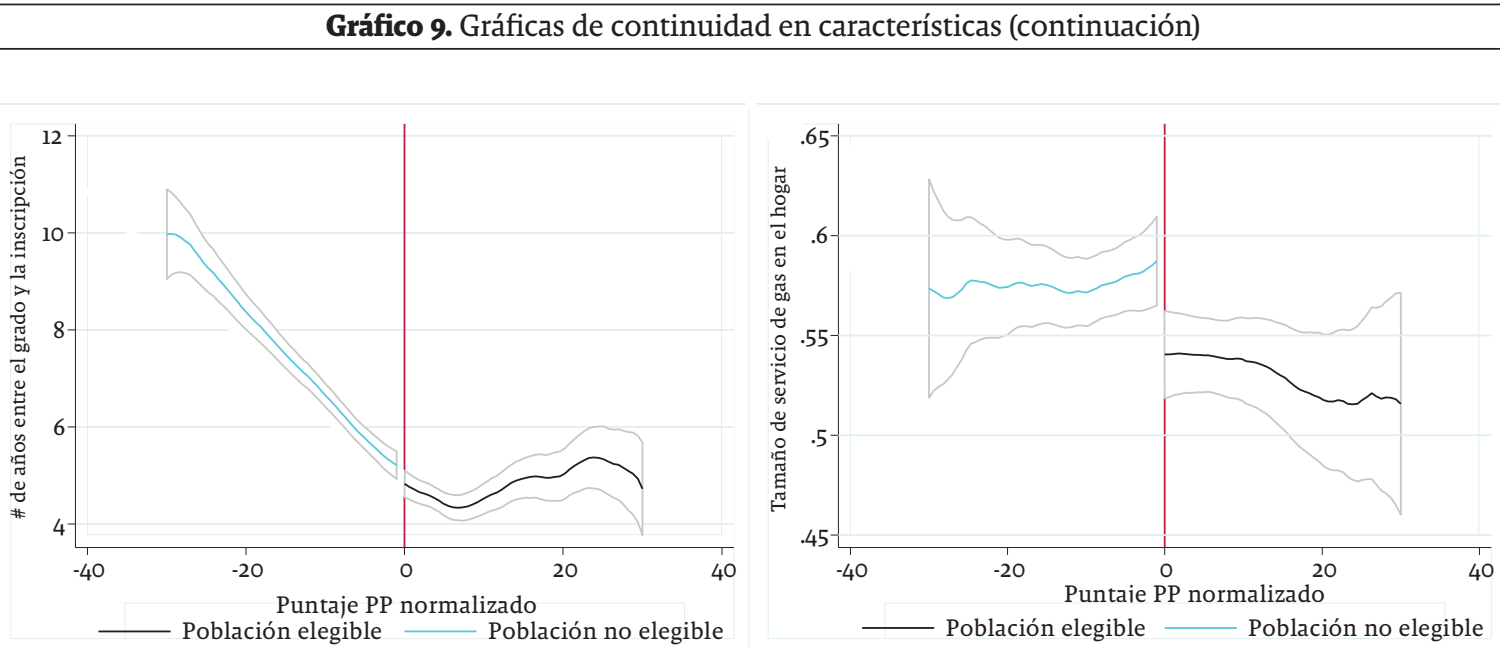

Fuente: elaboración de los autores con información de la base de inscritos y Sisbén 2015.

se podrían utilizar hacen parte del cálculo del puntaje del programa, como por ejemplo el estrato socioeconómico, el sector del colegio, etc.

De la base de inscritos, se seleccionó la edad al momento de la inscripción al programa, el sexo ( 1 es hombre) y si el aspirante es nacido en Medellín (1, si nació en Medellín) como características sociodemográficas iniciales. De la base del Sisbén, se calculó el tamaño del hogar, sexo (hombre) y edad del jefe del hogar al momento de la inscripción al programa, y tenencia de servicio de gas.

Se emplearon estas características, primero, porque no inciden en el cálculo del puntaje de elegibilidad de acuerdo con la regla de selección y, segundo, porque se supone que estas características son relativamente constantes en el tiempo. Ello significa, por un lado, que se asume que la jefatura del hogar no ha cambiado, por ejemplo. Para el caso del tamaño del hogar, al analizar algunas estadísticas para la población sisbenizada de Medellín, se puede mencionar que el promedio está entre 4,7 y 5 personas, valor que no muestra mayor variabilidad. No obstante, de acuerdo con las regresiones del Anexo 2, el tamaño del hogar sí muestra discontinuidad, al igual que la tenencia del servicio de gas. Se podrían haber tomado otras variables de la encuesta del Sisbén, pero es difícil poder argumentar ya sea que desde su postulación al programa dicha característica se ha mantenido constante o que el cambio se registró en igual medida tanto para elegibles como para no elegibles. Pese a ello, se encuentra continuidad en casi todas las variables de control. En el Anexo 2 se reportan las regresiones de la ecuación (8), considerando el total de inscritos.

Para validar la continuidad en las variables de control y previendo efectos de PLyPP, a largo plazo, se seleccionaron de la población tratada y no tratada aquellos inscritos que se postularon al programa hasta el 2010: II. La idea que hay detrás es que los programas de pregrado, específicamente las carreras profesionales universitarias, tienen en su gran mayoría una duración de cinco años, por lo que en 2010 prácticamente toda la población tratada (al menos la que no haya desertado) debió haber culminado sus estudios. En este sentido, puede esperarse la identificación de efectos superiores con esta selección muestral más pequeña.

En el Gráfico 10, se presenta la discontinuidad de las mismas variables de control, pero para esta submuestra. En el Anexo 3, se muestran son las estimaciones para cada ancho de banda.

Como se aprecia, en este caso se observa mayor 
Gráfico 10. Gráficas de continuidad para las características: Inscritos hasta el 2010

II
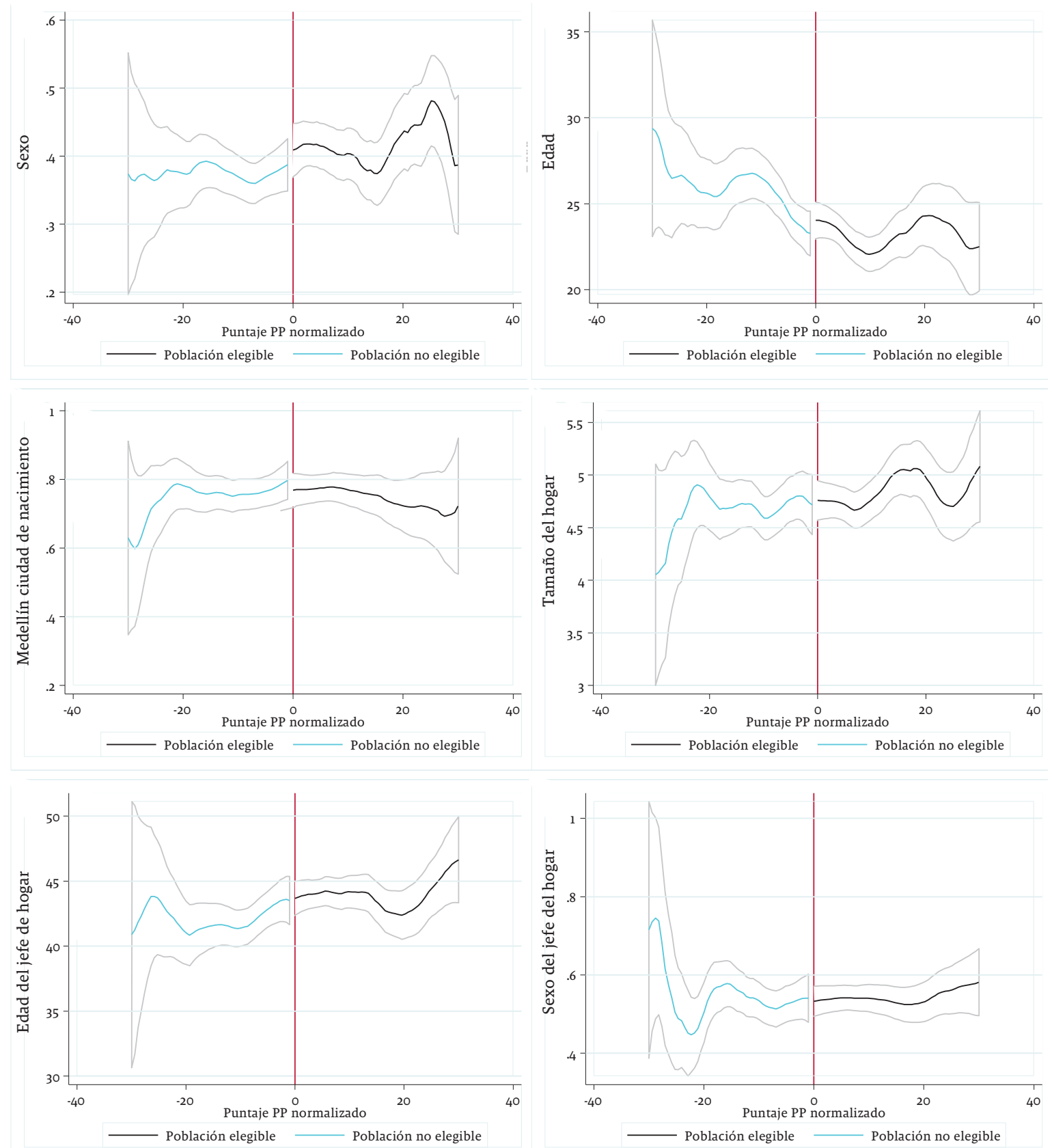

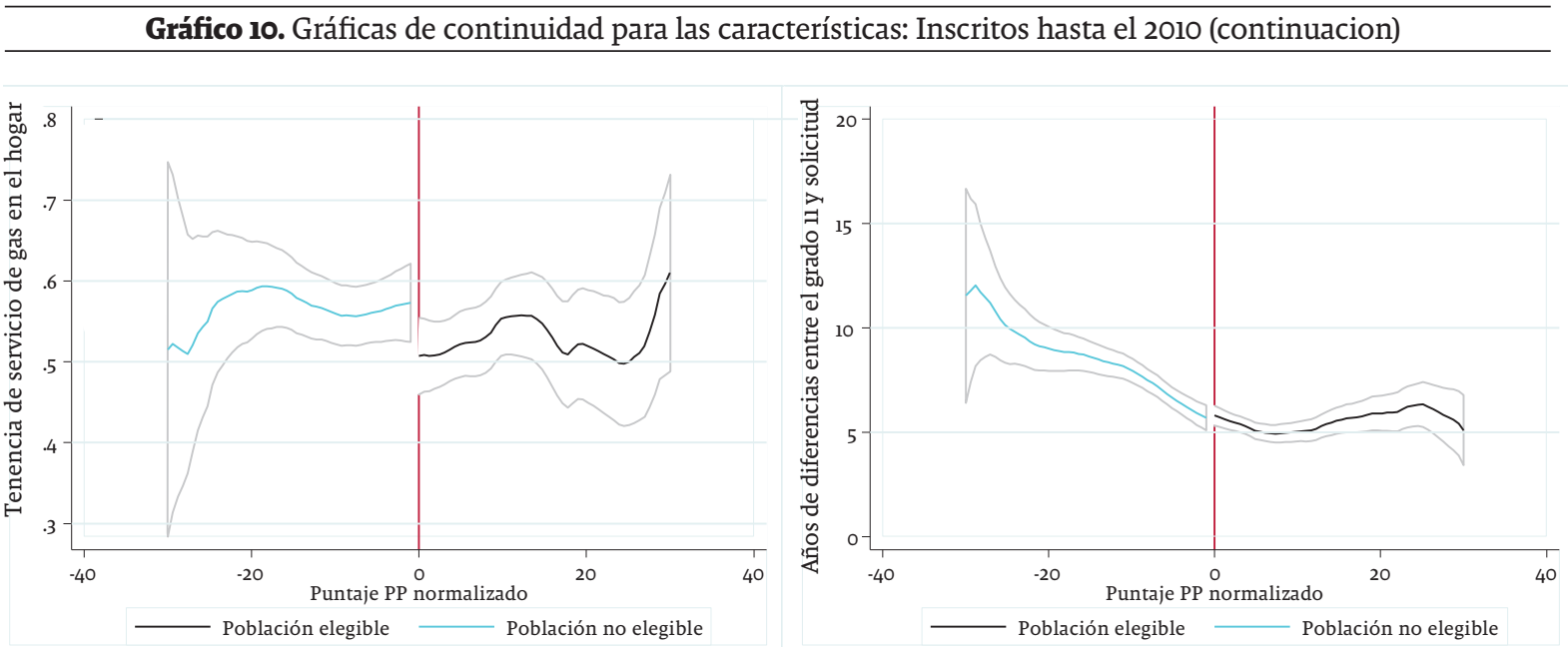

Fuente: elaboración de los autores con información de la base de inscritos y Sisbén 2015.

homogeneidad de la población elegible y no elegible alrededor del umbral, confirmando la continuidad de las variables control, supuesta clave de esta metodología.

Adicionalmente, como alternativa para verificar qué tan diferente es la población elegible de la no elegible en el margen, también se realiza el análisis gráfico de discontinuidad para los determinantes de la variable de asignación, es decir, de los criterios usados por Sapiencia para calcular el puntaje de cada inscrito. Aquí lo que se espera es que exista discontinuidad para la mayoría de estas variables decisoras, puesto que precisamente estas definen el puntaje $y$, por ende, la elegibilidad. En el Gráfico ll, se presentan los gráficos de discontinuidad para los determinantes y para el total de inscritos.

Como se observa, en la mayoría de los determinantes del puntaje de elegibilidad del tratamiento y en la variable de selección (última figura) se registra discontinuidad, siendo esto coherente con el mecanismo de elegibilidad del programa. No es el caso del puntaje en el Sisbén en línea base. Lo cual tiene explicación -y contribuye a defender el supuesto de similitud de ambas poblaciones-, basado en que el puntaje del Sisbén solo es utilizado para la variable de elegibilidad en los casos en que el aspirante es de estrato 4, 506 (Ver Anexo 1). Situación que, como ya se mostró, ocurre en menor porcentaje.

De igual forma, el nivel de formación deseado y sector del colegio registran continuidad. Esto se debe a que la mayoría de los estudiantes que se inscribieron provienen de colegios públicos -población que comparte un background socioeconómico similar y en la que precisamente este programa está enfocado-, y porque el nivel de formación más demandado es el profesional. Fenómeno que se presenta en ambos grupos.

Por lo tanto, y a manera de conclusión, hay suficiente evidencia como para determinar que la población tratada y no tratada en el margen es similar, validando la metodología del RD.

Finalmente, otra condición que requiere esta metodología es que ni los aspirantes ni el administrador del programa puedan manipular la elegibilidad alterando el puntaje. Ello significa que no debería observarse una discontinuidad en la función de densidad, alrededor del puntaje de corte normalizado, como se evidencia en el Gráfico 12.

\section{c. Análisis descriptivo}

La base final que se emplea es la que corresponde al cruce de los registros de PP con 
Gráfico 11 . Análisis de continuidad en los determinantes del puntaje de elegibilidad de PLyPP
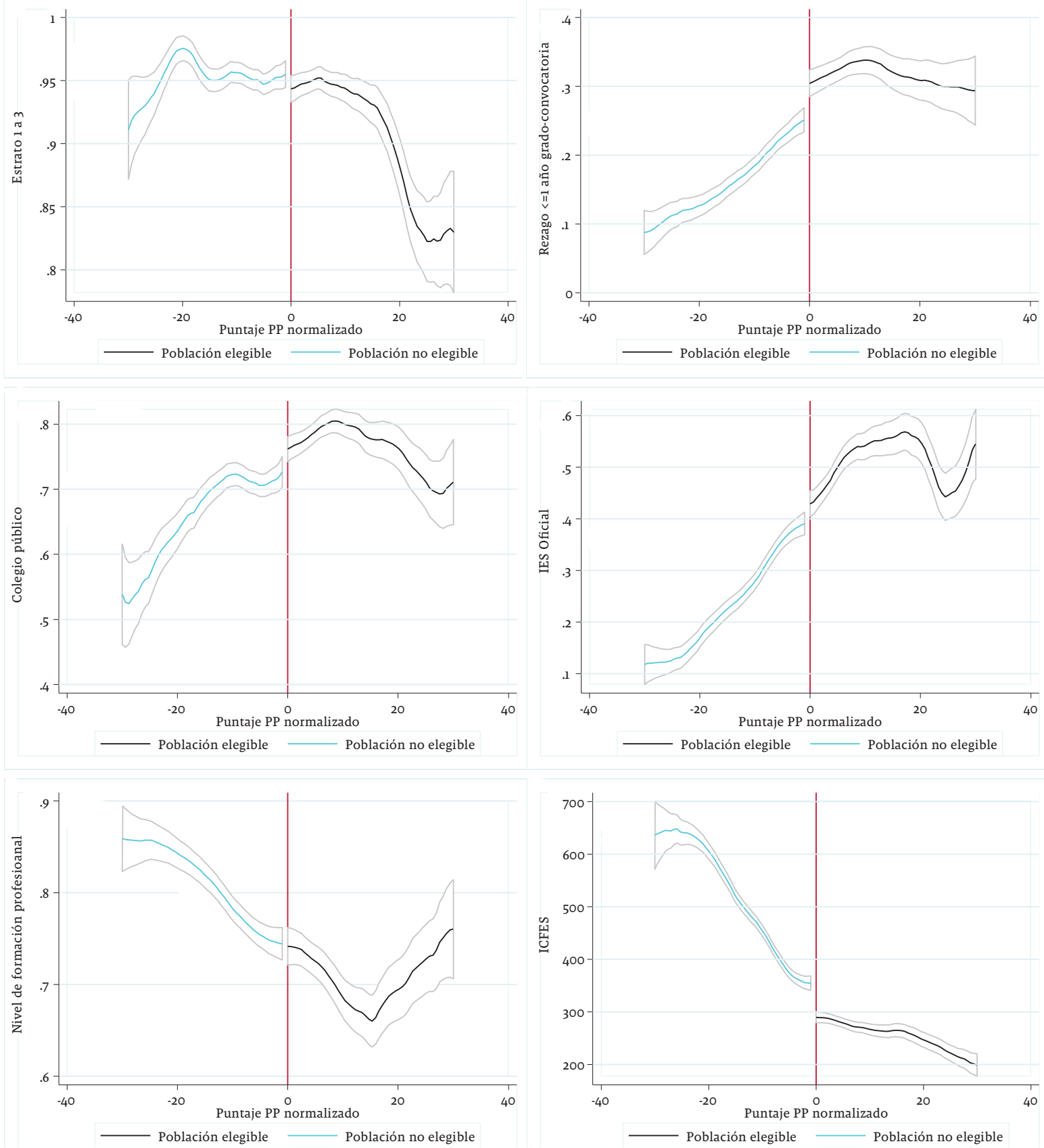
Gráfico Il. Análisis de continuidad en los determinantes del puntaje de elegibilidad de PLyPP (continuación)
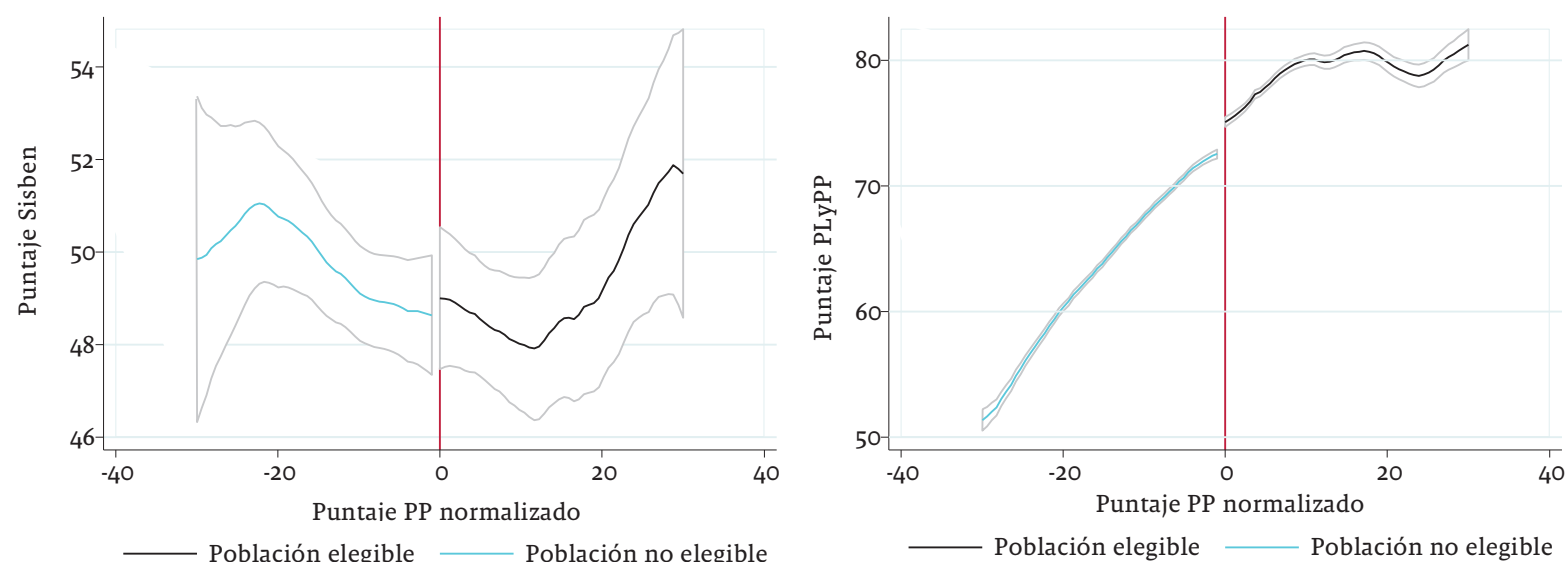

*En la figura de estrato 1 a 3 la variable corresponde a una dummy que toma el valor de 1 si el estrato es de 1 a 3. En la figura de Pruebas Saber ll se analiza es el puntaje. Se excluyeron los casos en que se asume que el resultado en el ICFES no es puntaje, sino rango de calificación.

Fuente: elaboración de los autores con información de la base de inscritos y Sisbén 2015.

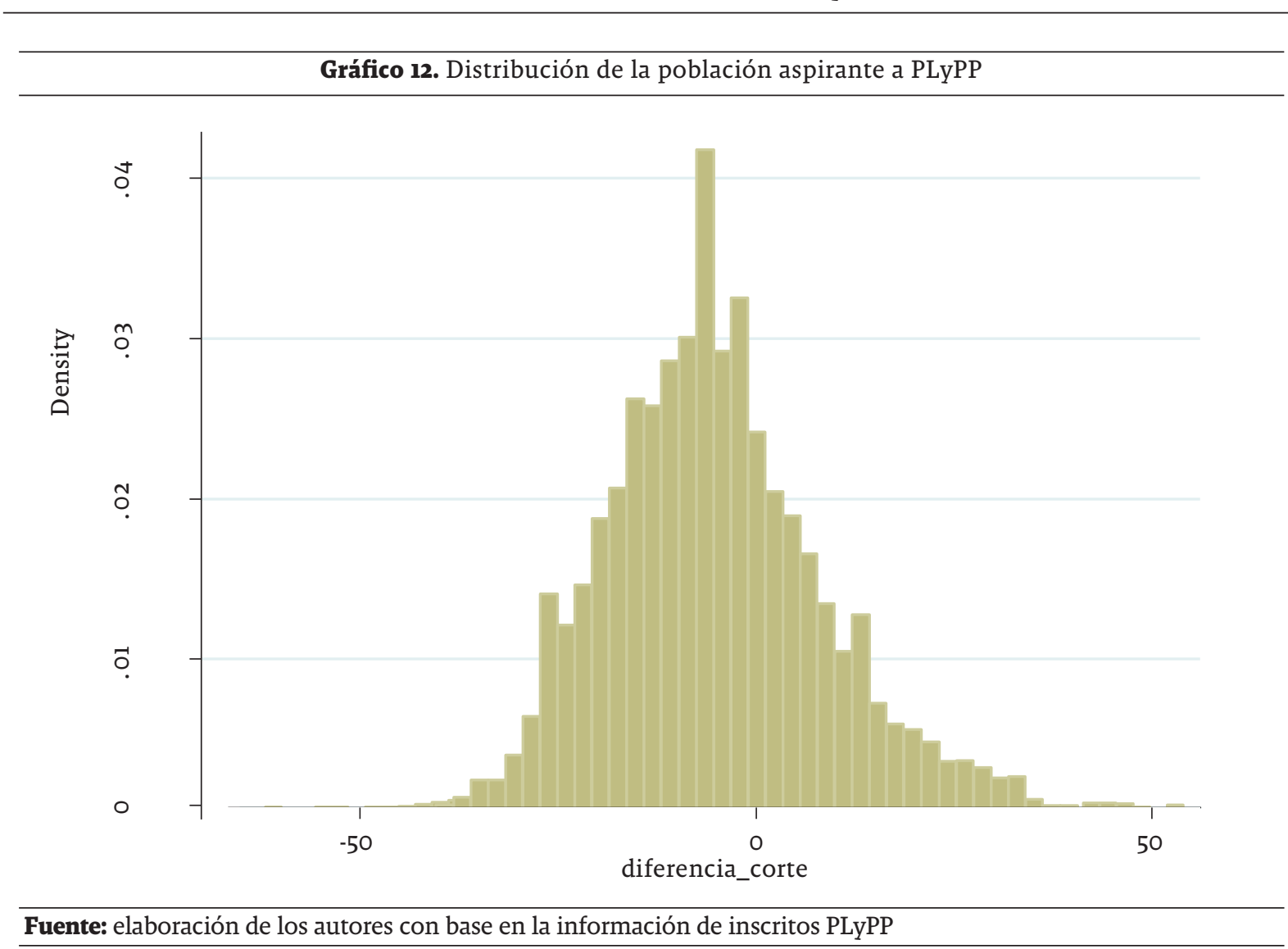


los del Sisbén. De este cruce, se identifican un total de 15.636 registros de PP en Sisbén de los 21.615 (equivalente al 72,3\%). De estos, al eliminar los registros duplicados, se tienen 12.989 registros y al excluir, con el fin de tener un ejercicio más limpio, las observaciones que tienen un puntaje superior al corte, pero están reportados como no aprobados o elegibles (1.448) -situación que se supone fue producto de falta de documentación o por incumplimiento de alguno de los requisitos habilitantes-, se tienen al final 11.926 registros pareados.

Las principales estadísticas descriptivas para el total de inscritos y para los que cruzaron con Sisbén 2015 (sin duplicados en ambos casos) se presentan en la Tabla 1. El 85,4\% de la población inscrita es soltera, mientras que el $22,1 \%$ de las mujeres tienen hijos, a 2015, y menos del 10\% han mejorado de estrato entre la fecha de postulación y el año de seguimiento. El 22\% están trabajando y de acuerdo con el Sisbén de 2015, el ingreso mensual total es del orden de $\$ 102.846$, aunque si se omiten los ingresos iguales a cero (por supuesta omisión), asciende a \$477.441. El $60,3 \%$ manifestaron, en el Sisbén, que se encuentran estudiando. El 18,3\%, en estudios superiores $\mathrm{y}$, de estos, aproximadamente la mitad lo hacen en instituciones públicas (el 47,7\%).

De los inscritos al programa, el $38 \%$ son hombres. Casi la mitad provienen de hogares cuyo estrato es 2 (consistente con la focalización del programa), la edad promedio al momento de postularse es de 22 años, el $77 \%$ son nacidos en Medellín, 9 de cada 10 residían al momento de aplicar en la zona urbana, el puntaje Sisbén promedio es de 49 puntos -considerablemente superior al puntaje estándar de focalización de programas sociales en Medellín (alrededor de los 32 puntos)-. Más del $70 \%$ de los que aplicaron son bachilleres de colegios públicos, más

\begin{tabular}{|c|c|c|c|c|}
\hline \multirow[t]{2}{*}{ Variable } & \multicolumn{2}{|c|}{ Base inicial depurada } & \multicolumn{2}{|c|}{ Base final cruzada } \\
\hline & Media & Desv. Est. & Media & Desv. Est. \\
\hline Estrato (LB) & 2,36 & 0,79 & 2,29 & 0,77 \\
\hline Edad (LB) & 21,96 & 6,09 & 21,99 & 6,01 \\
\hline Hombre* & 38,03 & & 37,79 & \\
\hline Nacido en Medellín* & 77,13 & & 77,87 & \\
\hline Residencia en comuna (urbano)* & 90,42 & & 87,46 & \\
\hline Puntaje Sisbén (LB) & 49,19 & 14,47 & 49 & 14,07 \\
\hline Colegio público* & 72,25 & & 74,51 & \\
\hline IES seleccionada pública* & 36,67 & & 38,16 & \\
\hline Rezago >1 año inscripción vs grado* & 24,19 & & 20,87 & \\
\hline Nivel de formación profesional* & 75,88 & & 75,42 & \\
\hline Puntaje PP & 71,08 & 10,73 & 70,84 & 10,41 \\
\hline Aprobados* & 35,96 & & 35,90 & \\
\hline Estado civil (soltero)* & & & 85,44 & \\
\hline Población estudiando (Sisbén)* & & & 60,37 & \\
\hline Población en ed. superior (Sisbén)* & & & 18,26 & \\
\hline Población en IES pública (Sisbén)* & & & 47,74 & \\
\hline Población ocupada* & & & 22,32 & \\
\hline Tenencia de hijos* & & & 22,11 & \\
\hline Ingreso mensual total & & & 102.846 & 229.858 \\
\hline Ingreso familiar per cápita & & & 172.866 & 199.156 \\
\hline Población que mejora de estrato* & & & 9,70 & \\
\hline $\mathbf{N}$ & & & & \\
\hline
\end{tabular}

Nota: * El dato del promedio equivale al porcentaje. LB significa cifra en línea base.

Fuente: cálculos propios, a partir de la base de inscritos PP y Sisbén 2015. 
de la tercera parte aspira a ingresar a una IES pública de la ciudad, 2 de cada 10 aplicaron, a lo sumo, al año de haberse graduado como bachiller y tres cuartas partes aspiran a cursar una carrera universitaria. El puntaje promedio, calculado por el programa, es del orden de 71 puntos y el porcentaje de aprobados es del $36 \%$.

\section{Resultados}

La distribución y estadísticas descriptivas de la mayoría de las variables definidoras del puntaje de PLyPP, de control y de impacto para la población tratada y no tratada en todo el periodo de análisis, se detallan en la Tabla 2 y Tabla 3.

Los porcentajes de la Tabla 2 indican, como es de esperarse, que en los determinantes del puntaje del programa (la variable de elegibilidad) la población tratada registra un favorable o mayor valor frente a la no tratada: colegio público, tiempo transcurrido no mayor a un año entre la fecha de graduación de bachillerato y presentación a la convocatoria, e IES pública deseada, por ejemplo, características que le otorgan al aspirante una mayor calificación (que para elegibles es obviamente superior: 78,4 vs 66,7$)$. Con respecto al puntaje del Sisbén en línea base, esto es, al momento de la inscripción al programa, hay coherencia con que el puntaje promedio para la población tratada sea inferior; lo mismo para el caso del estrato, aunque la diferencia no es estadísticamente significativa como sucede también con la condición de jefe de hogar, la cual no supera el 10\%.

En cuanto a las variables de impacto, se identifica -producto del cruce con el Sisbén- que la tenencia de hijos, la ocupación y la recepción de ingresos son situaciones menos recurrentes en la población tratada.

De igual manera, se evidencia que alrededor de dos terceras partes del grupo tratado se encuentran estudiando, mientras que para el no tratado esta actividad significa el 50\%, Si se considera el estudio como actividad, en el último mes, los por-

\begin{tabular}{|c|c|c|c|}
\hline Variable & Tratados & No tratados & $\#^{*}$ \\
\hline IES deseada Pública & $50,5 \%$ & $28,9 \%$ & 5.479 \\
\hline Colegio Público & $77,5 \%$ & $69,5 \%$ & 10.276 \\
\hline Residencia en zona Urbana & $86,4 \%$ & $90,8 \%$ & 14.185 \\
\hline Hombre & $40,3 \%$ & $36,7 \%$ & 6.259 \\
\hline Nacido en Medellín & $78,4 \%$ & $76,6 \%$ & 10.493 \\
\hline Rezago <=l año inscripción vs grado & $32,1 \%$ & $19,6 \%$ & 3.695 \\
\hline Técnica Pro. & $2,1 \%$ & $2,2 \%$ & 315 \\
\hline \multirow{2}{*}{$\begin{array}{ll}\text { Nivel de formación deseada } & \text { Tecnología } \\
& \text { Universitaria }\end{array}$} & $26,4 \%$ & $19,3 \%$ & 3.202 \\
\hline & $71,5 \%$ & $78,2 \%$ & 11.173 \\
\hline Estado civil soltero & $89,0 \%$ & $83,3 \%$ & 10.099 \\
\hline Población estudiando (Sisbén) & $63,7 \%$ & $49,8 \%$ & 6.477 \\
\hline Población estudiando² (Sisbén) & $31,3 \%$ & $44,4 \%$ & 4.703 \\
\hline Población en ed. superior (Sisbén) & $66,7 \%$ & $52,9 \%$ & 6.843 \\
\hline Población en IES pública (Sisbén) & $85,8 \%$ & $79,9 \%$ & 5.635 \\
\hline Población ocupada & $16,9 \%$ & $25,5 \%$ & 2.656 \\
\hline Tenencia de hijos & $16,7 \%$ & $25,1 \%$ & 1.636 \\
\hline Población que mejora de estrato & $10,1 \%$ & $9,5 \%$ & 1.084 \\
\hline Percibe ingresos al mes & $21,2 \%$ & $29,8 \%$ & 3.166 \\
\hline
\end{tabular}

Nota: *Corresponde al total de la población (elegible y no elegible) que cuenta con la característica definida por la variable. 1 se calcula a partir de la pregunta en el Sisbén: “¿Asiste a centro educativo?”. 2 se calcula a partir de la pregunta: "Actividad en el último mes" y se seleccionan los que respondan "Estudiando".

Fuente: cálculos propios, a partir del cruce de la base de inscritos PP y Sisbén 2015. 


\begin{tabular}{l|cccc}
\hline \multicolumn{3}{c}{ Tabla 3. Estadísticas descriptivas según población elegible y no elegible } \\
\hline \multicolumn{1}{c}{ Variable } & \multicolumn{2}{c}{ Tratados } & \multicolumn{2}{c}{ No tratados } \\
\cline { 2 - 5 } & Media & Des. Est. & Media & Des. Est. \\
\hline Ingreso mensual total & 75.517 & 202.350 & 116.686 & 243.606 \\
Ingreso familiar* & 892.339 & 744.189 & 877.861 & 685.882 \\
Ingreso familiar per cápita* & 205.542 & 183.918 & 208.804 & 210.181 \\
Estrato & 2,32 & 0,86 & 2,37 & 0,76 \\
Tamaño del hogar & 4,77 & 2 & 4,74 & 2,2 \\
Edad & 20,4 & 4,9 & 22,7 & 6,4 \\
Puntaje Sisbén (LB) & 48,7 & 14,2 & 49,6 & 14,6 \\
Puntaje Sisbén (FU)** & 50,6 & 13,9 & 50,9 & 13,8 \\
Puntaje PP & 78,4 & 8,5 & 66,7 & 9,3 \\
\hline
\end{tabular}

Notas: * Se excluyeron los casos en que el ingreso registrado fuera igual a cero.

** Corresponde al puntaje del Sisbén Follow up a 2015.

Fuente: cálculos propios, a partir del cruce de la base de inscritos PP y Sisbén 2015.

centajes son inferiores y pasan a ser $31 \%$ y $44 \%$, respectivamente. Así mismo, están estudiando con una diferencia de 13 puntos porcentuales, en mayor porcentaje, en carreras universitarias que, por lo general, tienen una duración de 10 semestres, sugiriendo que los tratados no solamente se encuentran estudiando en mayor proporción, sino también que lo hacen a mayor duración. Finalmente, al considerar el puntaje del Sisbén, en $\mathbf{2 0 1 5}$, se evidencia que no hay diferencia estadísticamente significativa entre ambos grupos. Situación que no implica que PLyPP no haya servido para mejorar la calificación de los elegibles, puesto que dicha calificación depende de muchas otras variables o dimensiones, como por ejemplo que los hogares tienen incentivos para mantener su puntaje lo más bajo posible, con la intención de tener mayores probabilidades de ingresar a los programas sociales del Estado.

Por su parte, la Tabla 3 representa las estadísticas descriptivas para ocho variables de interés. En el caso de los ingresos individuales y el familiar per cápita se reporta un promedio y desviación inferior para el grupo tratado, mas no para el del hogar. Esta menor renta mensual para la población elegible es justificable en el sentido en que ha destinado parte de su tiempo al estudio, generándose un costo de oportunidad de esta actividad que se traduce finalmente en una menor posibilidad de percibir ingresos y en montos menores. En cuanto al tamaño y estrato del hogar y el puntaje en el Sisbén (al momento de la aplicación) no hay diferencia estadísticamente significativa, pero sí para la edad y por supuesto, para el puntaje en PLyPP, pues es de esperarse, que la población tratada registre en promedio una mayor calificación a la no elegible. Esta discontinuidad también se identifica en las figuras del Gráfico 13.

Teniendo presente lo anterior, ahora se pasa a estimar el efecto de PLyPP en cada una de las variables de impacto de interés. En el Gráfico 13, se muestran las gráficas de discontinuidad asociadas con los outcomes mencionados, las cuales son muy útiles no solo para identificar si existen o no saltos en el umbral, sino también para determinar la forma funcional del efecto.

Se observa inicialmente una discontinuidad en las figuras, que se deben validar con las estimaciones. No se observan cambios fuertes de pendientes y las aproximaciones lineales parecen ser una correcta especificación, aprovechando los rangos cortos que se emplean alrededor del corte.

Sin embargo, para efectos de comparabilidad y conclusiones, se estiman las cuatro regresiones (ecuaciones (3), (5), (6) y (7)) para las variables de impacto y con los seis rangos de puntaje alrededor del punto de corte $(P N=0)$. Estos intervalos se 


\section{Gráfico 13. Gráficos de discontinuidad para la identificación del efecto de PLyPP}
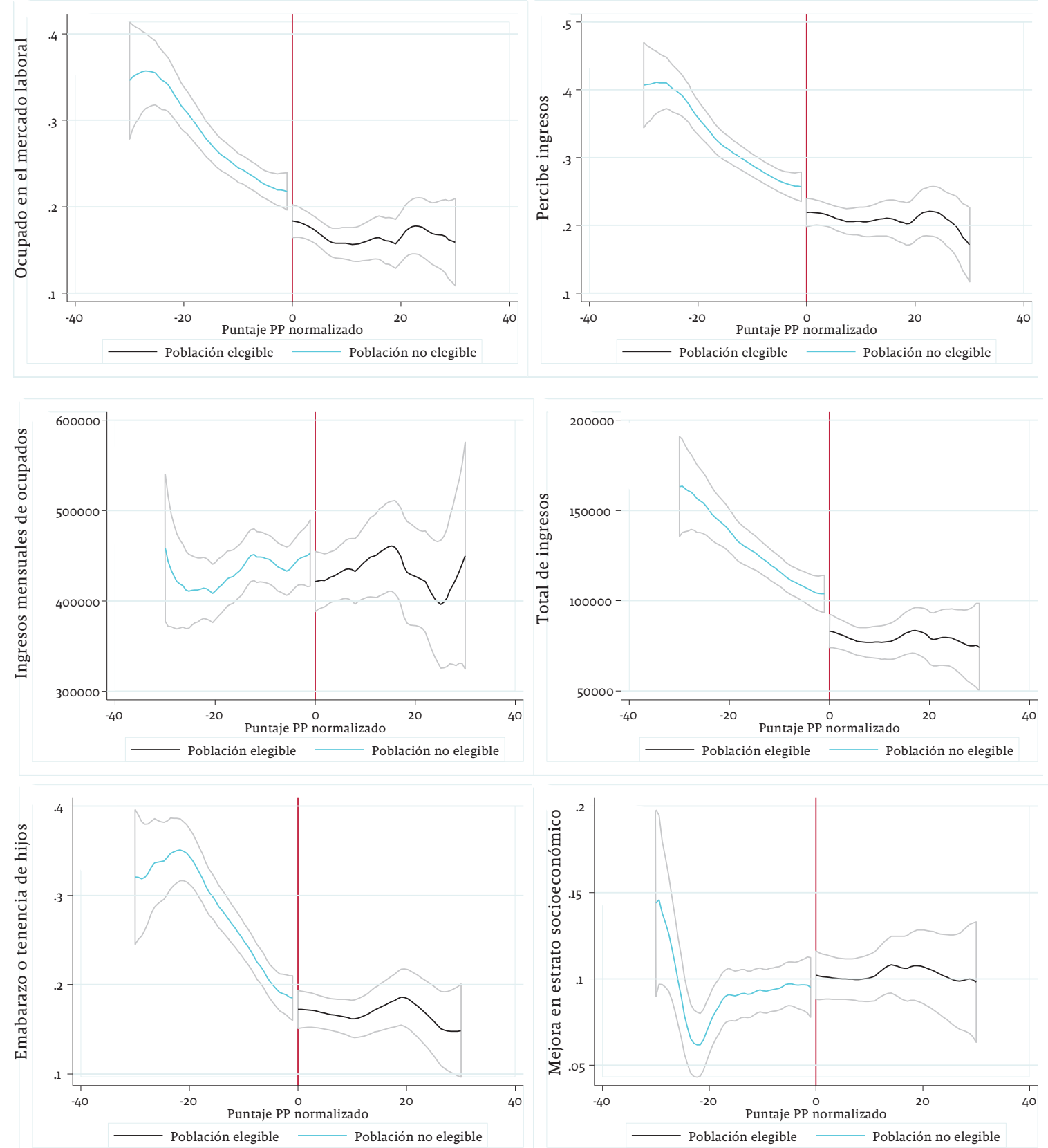

Fuente: elaboración de los autores con base en la información de inscritos y Sisbén 2015. 
van acotando desde un rango de +-10 hasta +-1, y entre más reducido sea este, los individuos tenderán a ser más similares, tal como se demostró con las regresiones del Anexo 2 y 3 y en los Gráfi$\cos 9$, 10 y 11 de la sección anterior.

Los outcomes se controlan con las covariables ya indicadas en el anterior capítulo: la variable de asignación (normalizado), la dummy de tratamiento $(D)$ y los efectos fijos de territorio, considerando las observaciones de todos los inscritos que cruzaron con el Sisbén 2015. Los resultados se sintetizan en los cuatro paneles del Cuadro 6, en el que se reporta para cada outcome la dirección del efecto, su valor y el tamaño muestral, y se indica la significancia estadística del efecto para cada uno de los seis anchos de banda.

Los resultados indican, en términos generales, que -si bien varios de los coeficientes no son estadísticamente significativos para el caso del impacto en la ocupación-, la dirección del efecto es siempre "negativo", contrario a lo inicialmente esperado. Lo mismo ocurre para los ingresos en sus tres formas, en los que los coeficientes significativos tienen el signo negativo. Esto indica lo mismo que se halló en la Tabla 2 y la Tabla 3: los beneficiarios incurren en el costo de oportunidad de estudiar y, por tanto, al encontrarse estudiando, no pueden tener trabajos; o si los tienen, difícilmente pueden ser de jornada completa y percibirán menores ingresos. En consecuencia, un efecto local inicial de PLyPP es que restringe la ocupación de los beneficiarios en el margen, al estar desarrollando la actividad de estudio y al esforzarse por salvaguardar la cofinanciación de la carrera manteniendo el promedio por encima del mínimo exigido. Por lo tanto, los ingresos de corto plazo se ven reducidos. Es de esperar que, a más largo plazo, la población beneficiaria -gracias a su acceso a la educación superior y bajo la luz de la teoría del capital humano- tenga mejores posibilidades de engancharse en el mercado laboral y sea mejor remunerada.

Con respecto al estado civil, los resultados a partir de las regresiones lineales indican un efecto positivo del orden del 6,8\% en la posibilidad de perder la soltería. Aunque potencialmente esto no es concluyente por la baja representatividad que tienen en la muestra las personas con un estado civil distinto al de nacimiento (el $85 \%$ del total de los inscritos son solteros). Frente al embarazo o tenencia de hijos, no se encuentra efecto alguno de PLyPP: ninguna de las estimaciones es estadísticamente significativa y no se pueden hacer conclusiones sobre la eventual dirección del efecto. Finalmente, para el caso de la mejora en la calidad de vida -medida a través de la migración a un estrato más alto- si bien la dirección del impacto es positiva, ninguna es estadísticamente significativa.

La validación de estos efectos se realiza en primer lugar con la selección de los inscritos hasta 2010:II. Los resultados de la evaluación empleando las cuatro ecuaciones $(3,5,6$ y 7), las mismas covariables y los seis anchos de banda, incluyendo los inscritos hasta el 2010:II, se registran en los cuatro paneles de la Tabla 5 (de manera similar a como se presentó en la Tabla 4). Los gráficos de discontinuidad se presentan en el Anexo 4.

En este caso, el signo del efecto en la ocupación es igualmente negativo $\mathrm{y}$, en un caso, es significativo (con la ecuación (3)) con un coeficiente del 9,4\%, por tanto, se respalda el impacto negativo que tiene PLyPP en la probabilidad de engancharse en el mercado laboral. Con respecto a los ingresos, se presentan esta vez más signos negativos y algunos de ellos estadísticamente significativos, lo que confirma la conclusión del Cuadro 6. Frente al cambio en el estado civil, si bien se registran más coeficientes con signo negativo, no hay significancia estadística. Con la tenencia de hijos, el impacto parece ser negativo, de PLyPP, del orden del $12 \%$. Esto indicaría que un efecto local de largo plazo esperable del programa es que se reduzca el embarazo. $\mathrm{Al}$ respecto, un eventual trabajo a futuro será incluir en la muestra a los hombres padres, para tener una idea global del efecto del presupuesto participativo.

Finalmente, en mejora del estrato, la mayoría de los coeficientes no son significativos, pero a partir de las ecuaciones (3) y (7) parece haber un efecto local del programa positivo cercano al $20 \%$, lo que evidencia que PLyPP contribuiría a mejorar de estrato socioeconómico. Conviene mencionar que la variable mejora incluye tanto a los que pasaron del estrato 1 a 2 como a los que pasaron del 5 al 6 y el resto de posibilidades. Se hizo el ejercicio adicional de considerar, para este último outcome, no solo la mejora sino el mantenerse en el estrato, con el fin 
Impactos iniciales de la financiación de la educación superior con recursos del presupuesto participativo: evidencia para Medellín

\begin{tabular}{|c|c|c|c|c|c|c|c|c|}
\hline \multicolumn{9}{|c|}{ PANEL A. Ecuación lineal (3) de igual pendiente } \\
\hline $\begin{array}{c}\text { Puntaje } \\
\text { alrededor del } \\
\text { corte }\end{array}$ & Ocupación & $\begin{array}{l}\text { Percibe } \\
\text { ingresos }\end{array}$ & $\begin{array}{l}\text { Ingresos } \\
\text { totales de } \\
\text { ocupados }\end{array}$ & $\begin{array}{l}\text { Ingresos } \\
\text { totales }\end{array}$ & $\begin{array}{c}\text { Ingreso } \\
\text { familiar } \\
\text { per cápita }\end{array}$ & $\begin{array}{l}\text { Pérdida de } \\
\text { soltería }\end{array}$ & $\begin{array}{c}\text { Tenencia } \\
\text { temprana } \\
\text { de hijos }\end{array}$ & $\begin{array}{c}\text { Mejora } \\
\text { de } \\
\text { estrato }\end{array}$ \\
\hline$(-10,10)$ & $-0,0264$ & $-0,0306$ & $-19.521,57$ & $-13.199,22$ & $-7.705,80$ & 0,0032 & $-0,0095$ & 0,0057 \\
\hline $\mathrm{n}=5.726$ & $(0,0181)$ & $(0,0194)$ & $(34.187,00)$ & $(10.537,38)$ & $(8.429,38)$ & $(0,0146)$ & $(0,0208)$ & $(0,0156)$ \\
\hline$(-5,5)$ & $-0,0422^{*}$ & $-0,0463^{*}$ & $-51.534,77$ & $-23.204,97 *$ & $-3.829,66$ & 0,0084 & $-0,0176$ & 0,0178 \\
\hline $\mathrm{n}=3.203$ & $(0,0240)$ & $(0,0259)$ & $(44.696,16)$ & $(13950,85)$ & $(10.920,59)$ & $(0,0193)$ & $(0,0276)$ & $(0,0204)$ \\
\hline$(-4,4)$ & $-0,0427$ & $-0,0379$ & $-35.207,46$ & $-18.675,66$ & $-6.069,62$ & 0,0073 & $-0,0121$ & 0,0190 \\
\hline $\mathrm{n}=2.617$ & $(0,0264)$ & $(0,0284)$ & $(50.992,72)$ & $(15.495,03)$ & $(12.247,11)$ & $(0,0215)$ & $(0,0307)$ & $(0,0229)$ \\
\hline$(-3,3)$ & $-0,0383$ & $-0,0281$ & $-39.915,99$ & $-15.798,61$ & $-5.660,14$ & 0,0118 & $-0,0076$ & 0,0078 \\
\hline $\mathrm{n}=2.150$ & $(0,0297)$ & $(0,0318)$ & $(55345,71)$ & $(17.428,74)$ & $(13.528,78)$ & $(0,0243)$ & $(0,0341)$ & $(0,0264)$ \\
\hline$(-2,2)$ & $-0,0448$ & $-0,0240$ & $-11.798,80$ & $-11.419,68$ & $2.59,87$ & 0,0128 & $-0,0226$ & 0,0337 \\
\hline$n=1.605$ & $(0,0342)$ & $(0,0370)$ & $(64.860,64)$ & $(19,789,08)$ & $(15.744,46)$ & $(0,0281)$ & $(0,0402)$ & $(0,0304)$ \\
\hline$(-1,1)$ & $-0,0671$ & $-0,0355$ & $-11.725,94$ & $-9.967,57$ & $1.767,58$ & $0,0679 *$ & 0,0179 & 0,0373 \\
\hline $\mathrm{n}=1.022$ & $(0,0467)$ & $(0,0506)$ & $(85.749,88)$ & $(26.383,46)$ & $(22.099,26)$ & $(0,0379)$ & $(0,0520)$ & $(0,0419)$ \\
\hline \multicolumn{9}{|c|}{ PANEL B. Ecuación cuadrática (5) de igual pendiente } \\
\hline$(-10,10)$ & $-0,0271$ & $-0,0305$ & $-21.587,60$ & $-13.265,76$ & $-7.948,40$ & 0,0030 & $-0,0087$ & 0,0050 \\
\hline $\mathrm{n}=5.726$ & $(0,0182)$ & $(0,0195)$ & $(33.923,47)$ & $(10.638,03)$ & $(8.416,20)$ & $(0,0146)$ & $(0,0209)$ & $(0,0156)$ \\
\hline$(-5,5)$ & $-0,0373$ & $-0,0379$ & $-51.717,81$ & $-21.591,06$ & $-4.504,39$ & 0,0109 & $-0,0128$ & 0,0192 \\
\hline $\mathrm{n}=3.203$ & $(0,0249)$ & $(0,0266)$ & $(45.981,38)$ & $(14.623,08)$ & $(11.288,76)$ & $(0,0198)$ & $(0,0282)$ & $(0,0208)$ \\
\hline$(-4,4)$ & $-0,0512^{*}$ & $-0,0463$ & $-36.043,58$ & $-21.804,77$ & $-11.687,13$ & 0,0106 & 0,0009 & 0,0221 \\
\hline $\mathrm{n}=2.617$ & $(0,0279)$ & $(0,0299)$ & $(54.885,29)$ & $(16.883,98)$ & $(12.630,72)$ & $(0,0223)$ & $(0,0319)$ & $(0,0236)$ \\
\hline$(-3,3)$ & $-0,0324$ & $-0,0251$ & $-33.254,64$ & $-12.998,47$ & $-6.078,76$ & 0,0285 & 0,0114 & 0,0269 \\
\hline $\mathrm{n}=2.150$ & $(0,0327)$ & $(0,0348)$ & $(60.000,96)$ & $(19.543,39)$ & $(14.789,58)$ & $(0,0258)$ & $(0,0364)$ & $(0,0275)$ \\
\hline$(-2,2)$ & $-0,0576$ & $-0,0372$ & $-49.769,65$ & $-22.795,98$ & $-1.345,55$ & 0,0306 & 0,0390 & 0,0353 \\
\hline$n=1.605$ & $(0,0431)$ & $(0,0461)$ & $(81.787,15)$ & $(26.202,29)$ & $(20.030,57)$ & $(0,0332)$ & $(0,0480)$ & $(0,0356)$ \\
\hline \multicolumn{9}{|c|}{ PANEL C. Ecuación lineal (6) de pendiente distinta } \\
\hline Entre -10 y 10 & $-0,0284$ & $-0,0301$ & $-19.252,12$ & $-13.616,83$ & $-8.696,77$ & 0,0030 & $-0,0062$ & 0,0035 \\
\hline $\mathrm{n}=5.726$ & $(0,0185)$ & $(0,0198)$ & $(34.292,53)$ & $(10.915,96)$ & $(84.55,15)$ & $(0,0148)$ & $(0,0211)$ & $(0,0157)$ \\
\hline$(-5,5)$ & $-0,0357$ & $-0,0361$ & $-53.777,40$ & $-21.945,12$ & $-6.013,28$ & 0,0135 & $-0,0052$ & 0,0220 \\
\hline $\mathrm{n}=3.203$ & $(0,0261)$ & $(0,0278)$ & $(48.339,82)$ & $(15.479,21)$ & $(11.787,49)$ & $(0,0205)$ & $(0,0294)$ & $(0,0215)$ \\
\hline$(-4,4)$ & $-0,0535^{*}$ & $-0,0504$ & $-39.335,15$ & $-23.826,69$ & $-15.341,27$ & 0,0140 & 0,0138 & 0,0271 \\
\hline$n=2.617$ & $(0,0299)$ & $(0,0320)$ & $(59.887,75)$ & $(18.457,87)$ & $(13.424,77)$ & $(0,0236)$ & $(0,0340)$ & $(0,0249)$ \\
\hline$(-3,3)$ & $-0,0285$ & $-0,0249$ & $-38.787,96$ & $-13.999,48$ & $-8.383,43$ & 0,0359 & 0,0302 & 0,0340 \\
\hline $\mathrm{n}=2.150$ & $(0,0365)$ & $(0,0387)$ & $(66.254,21)$ & $(21.985,36)$ & $(16.464,05)$ & $(0,0282)$ & $(0,0400)$ & $(0,0300)$ \\
\hline$(-2,2)$ & $-0,0594$ & $-0,0410$ & $-77.743,86$ & $-29.977,35$ & $-4.036,86$ & 0,0266 & 0,0660 & 0,0379 \\
\hline$n=1.605$ & $(0,0521)$ & $(0,0553)$ & $(99.662,48)$ & $(32.034,78)$ & $(24.161,34)$ & $(0,0391)$ & $(0,0577)$ & $(0,0419)$ \\
\hline$(-1,1)$ & $-0,0671$ & $-0,0355$ & $-11.725,94$ & $-9.967,57$ & $1.767,58$ & $0,0679^{*}$ & 0,0179 & \\
\hline$n=1.022$ & $(0,0467)$ & $(0,0506)$ & $(8.5749,88)$ & $(26.383,46)$ & $(22.099,26)$ & $(0,0379)$ & $(0,0520)$ & \\
\hline
\end{tabular}


Silvio Fernando López-Mera • David Eduardo Quintero-Rendón

Tabla 4. Efectos de la financiación de educación de pregrado con PLyPP (Continuación)

PANEL D. Ecuación cuadrática (7) de pendiente distinta

\begin{tabular}{c|cccccccc}
\hline Entre -10 y 10 & $-0,0500^{*}$ & $-0,0534 *$ & $-75.556,31$ & $-35.836,10 * *$ & $-13.991,36$ & 0,0035 & $-0,0113$ & 0,0253 \\
$\mathrm{n}=5.726$ & $(0,0287)$ & $(0,0306)$ & $(53.462,59)$ & $(17.369,96)$ & $(13.205,22)$ & $(0,0224)$ & $(0,0318)$ & $(0,0233)$ \\
\hline $\mathbf{( - 5 , 5 )}$ & $-0,0687$ & $-0,0640$ & $-42.496,38$ & $-27.511,32$ & $-21.047,01$ & 0,0391 & 0,0573 & 0,0364 \\
$\mathrm{n}=3.203$ & $(0,0485)$ & $(0,0517)$ & $(90.110,37)$ & $(29.785,23)$ & $(22.276,40)$ & $(0,0377)$ & $(0,0532)$ & $(0,0399)$ \\
\hline $\mathbf{( - 4 , 4 )}$ & $-0,0184$ & $-0,0075$ & $-72.119,58$ & $-16.102,44$ & 5.519 .05 & 0,0688 & 0,0699 & 0,0458 \\
$\mathrm{n}=2.617$ & $(0,0629)$ & $(0,0669)$ & $(120.285,14)$ & $(38.748,01)$ & $(28.464,05)$ & $(0,0486)$ & $(0,0689)$ & $(0,0519)$ \\
\hline $\mathbf{( - 3 , 3 )}$ & $-0,1414$ & $-0,0933$ & $-165.525,80$ & $-73785,68$ & $-3.853,02$ & 0,0038 & 0,1394 & 0,0312 \\
$\mathrm{n}=2.150$ & $(0,0983)$ & $(0,1033)$ & $(179.671,53)$ & $(58.864,89)$ & $(44.263,79)$ & $(0,0744)$ & $(0,1098)$ & $(0,0782)$ \\
\hline $\mathbf{( - 2 , 2 )}$ & $-0,0747$ & $-0,0475$ & $-13.025,29$ & $-16.193,85$ & $1.807,45$ & $0,0802 *$ & 0,0528 & 0,0285 \\
$\mathrm{n}=1.605$ & $(0,0550)$ & $(0,0591)$ & $(98.837,10)$ & $(31.159,19)$ & $(26.103,10)$ & $(0,0437)$ & $(0,0611)$ & $(0,0478)$ \\
\hline
\end{tabular}

Notas: ${ }^{*},{ }^{* *} \mathrm{y}^{* * *}$ corresponden a un nivel de significancia del $10 \%, 5 \%$ y $1 \%$ respectivamente.

El dato entre paréntesis debajo del coeficiente del efecto es la desviación estándar robusta.

Fuente: elaboración de los autores con base en la información de inscritos y Sisbén 2015.

Tabla 5. Efectos a 2015 de la financiación de educación de pregrado con PLyPP para inscritos hasta el 2010

\begin{tabular}{|c|c|c|c|c|c|c|c|c|}
\hline \multicolumn{9}{|c|}{ PANEL A. Ecuación lineal (3) de igual pendiente } \\
\hline $\begin{array}{c}\text { Puntaje } \\
\text { alrededor del } \\
\text { corte }\end{array}$ & Ocupación & $\begin{array}{c}\text { Percibe } \\
\text { ingresos }\end{array}$ & $\begin{array}{c}\text { Ingresos } \\
\text { totales de } \\
\text { ocupados }\end{array}$ & $\begin{array}{l}\text { Ingresos } \\
\text { totales }\end{array}$ & $\begin{array}{c}\text { Ingreso } \\
\text { familiar } \\
\text { per cápita }\end{array}$ & $\begin{array}{c}\text { Pérdida de } \\
\text { soltería }\end{array}$ & $\begin{array}{c}\text { Tenencia } \\
\text { temprana } \\
\text { de hijos }\end{array}$ & $\begin{array}{c}\text { Mejora } \\
\text { de } \\
\text { estrato }\end{array}$ \\
\hline$(-10,10)$ & $-0,0353$ & $-0,0389$ & $-63.746,67$ & $-28.002,49$ & $-12.264,74$ & $-0,0257$ & $-0,0710$ & $-0,0499$ \\
\hline $\mathrm{n}=1.553$ & $(0,0417)$ & $(0,0429)$ & $(50.953,94)$ & $(24.358,47)$ & $(15.745,74)$ & $(0,0342)$ & $(0,0527)$ & $(0,0378)$ \\
\hline$(-5,5)$ & $-0,0937^{*}$ & $-0,0999 *$ & $-82.617,97$ & $-63.543,19^{*}$ & $-22.207,01$ & $-0,0118$ & $-0,1199 *$ & $-0,0318$ \\
\hline $\mathrm{n}=884$ & $(0,0556)$ & $(0,0571)$ & $(69.300,21)$ & $(33.157,31)$ & $(20.819,86)$ & $(0,0449)$ & $(0,0696)$ & $(0,0520)$ \\
\hline$(-4,4)$ & $-0,0761$ & $-0,0815$ & $-63.841,92$ & $-47.419,11$ & $-7.662,41$ & 0,0004 & $-0,1076$ & $-0,0507$ \\
\hline $\mathrm{n}=741$ & $(0,0600)$ & $(0,0620)$ & $(78.109,17)$ & $(36.356,45)$ & $(22.910,30)$ & $(0,0482)$ & $(0,0757)$ & $(0,0582)$ \\
\hline$(-3,3)$ & $-0,0838$ & $-0,0800$ & $-49.802,79$ & $-43.568,74$ & $-10.496,66$ & $-0,0220$ & $-0,1076$ & $-0,0342$ \\
\hline $\mathrm{n}=623$ & $(0,0656)$ & $(0,0674)$ & $(82.898,40)$ & $(39.226,54)$ & $(25.252,58)$ & $(0,0523)$ & $(0,0830)$ & $(0,0651)$ \\
\hline$(-2,2)$ & $-0,0663$ & $-0,0539$ & $-46.876,13$ & $-19.462,31$ & $-15.499,34$ & $-0,0064$ & $-0,1562$ & 0,0490 \\
\hline $\mathrm{n}=447$ & $(0,0779)$ & $(0,0796)$ & $(97.364,17)$ & $(46.263,13)$ & $(28.872,50)$ & $(0,0627)$ & $(0,1035)$ & $(0,0780)$ \\
\hline$(-1,1)$ & $-0,0858$ & $-0,0742$ & $-97.810,90$ & $-20.151,81$ & $-47.219,70$ & 0,0436 & $-0,1358$ & $0,2072^{*}$ \\
\hline & $(0,1064)$ & $(0,1099)$ & $(135.132,79)$ & $(61.348,80)$ & $(46.580,17)$ & $(0,0882)$ & $(0,1484)$ & $(0,1085)$ \\
\hline \multicolumn{9}{|c|}{ PANEL B . Ecuación cuadrática (5) de igual pendiente } \\
\hline$(-10,10)$ & $-0,0445$ & $-0,0456$ & $-66.094,97$ & $-35.063,36$ & $-16.328,57$ & $-0,0275$ & $-0,0575$ & $-0,0590$ \\
\hline$n=1,553$ & $(0,0427)$ & $(0,0439)$ & $(51.664,39)$ & $(25.335,13)$ & $(16.113,31)$ & $(0,0351)$ & $(0,0536)$ & $(0,0394)$ \\
\hline$(-5,5)$ & $-0,0940$ & $-0,1088^{*}$ & $-97.126,80$ & $-70.008,58^{* *}$ & $-21.811,53$ & $-0,0190$ & $-0,1281 *$ & $-0,0163$ \\
\hline $\mathrm{n}=884$ & $(0,0578)$ & $(0,0594)$ & $(75.281,69)$ & $(35.170,65)$ & $(21.985,55)$ & $(0,0460)$ & $(0,0714)$ & $(0,0574)$ \\
\hline$(-4,4)$ & $-0,0949$ & $-0,1131^{*}$ & $-47.479,50$ & $-53.145,05$ & $-10.560,68$ & $-0,0025$ & $-0,1148$ & $-0,0542$ \\
\hline $\mathrm{n}=741$ & $(0,0641)$ & $(0,0662)$ & $(88.789,75)$ & $(40.101,67)$ & $(25.238,27)$ & $(0,0511)$ & $(0,0803)$ & $(0,0621)$ \\
\hline$(-3,3)$ & $-0,0230$ & $-0,0365$ & $-6.986,14$ & $-6.885,35$ & $-5.238,44$ & 0,0318 & $-0,0870$ & 0,0298 \\
\hline $\mathrm{n}=623$ & $(0,0749)$ & $(0,0768)$ & $(95.485,65)$ & $(46.549,87)$ & $(29.300,21)$ & $(0,0582)$ & $(0,0907)$ & $(0,0753)$ \\
\hline$(-2,2)$ & $-0,0670$ & $-0,0376$ & $-31.466,49$ & $-13.026,77$ & $-47.620,95$ & $-0,0045$ & $-0,0643$ & 0,1388 \\
\hline $\mathrm{n}=447$ & $(0,0988)$ & $(0,1021)$ & $(132.346,69)$ & $(62.885,99)$ & $(38.132,02)$ & $(0,0769)$ & $(0,1284)$ & $(0,0999)$ \\
\hline
\end{tabular}


Impactos iniciales de la financiación de la educación superior con recursos del presupuesto participativo: evidencia para Medellín

\begin{tabular}{|c|c|c|c|c|c|c|c|c|}
\hline \multicolumn{9}{|c|}{ PANEL C. Ecuación lineal (6) de pendiente diferente } \\
\hline$(-10,10)$ & $-0,0450$ & $-0,0470$ & $-68.224,03$ & $-36.762,55$ & $-17.394,88$ & $-0,0246$ & $-0,0522$ & $-0,0595$ \\
\hline $\mathrm{n}=1.553$ & $(0,0437)$ & $(0,0449)$ & $(53.225,78)$ & $(26.164,58)$ & $(16.437,14)$ & $(0,0358)$ & $(0,0545)$ & $(0,0406)$ \\
\hline$(-5,5)$ & $-0,0918$ & $-0,1133^{*}$ & $-102.716,42$ & $-72.945,94^{*}$ & $-23.441,16$ & $-0,0175$ & $-0,1246^{*}$ & $-0,0085$ \\
\hline $\mathrm{n}=884$ & $(0,0607)$ & $(0,0624)$ & $(8.1035,32)$ & $(37.234,46)$ & $(23.490,78)$ & $(0,0478)$ & $(0,0744)$ & $(0,0603)$ \\
\hline$(-4,4)$ & $-0,0883$ & $-0,1151$ & $-43.550,60$ & $-51.737,45$ & $-11.062,39$ & 0,0068 & $-0,1013$ & $-0,0538$ \\
\hline $\mathrm{n}=741$ & $(0,0691)$ & $(0,0714)$ & $(98.073,69)$ & $(43.706,31)$ & $(27.914,48)$ & $(0,0547)$ & $(0,0855)$ & $(0,0652)$ \\
\hline$(-3,3)$ & $-0,0017$ & $-0,0214$ & $1.044,60$ & 233,70 & $-5.579,31$ & 0,0479 & $-0,0573$ & 0,0402 \\
\hline $\mathrm{n}=623$ & $(0,0839)$ & $(0,0861)$ & $(105.401,02)$ & $(52383,39)$ & $(33.391,28)$ & $(0,0649)$ & $(0,0985)$ & $(0,0821)$ \\
\hline$(-2,2)$ & $-0,0619$ & $-0,0256$ & $-51.794,84$ & $-17.953,76$ & $-60.109,23$ & $-0,0215$ & $-0,0062$ & 0,1395 \\
\hline$n=447$ & $(0,1221)$ & $(0,1264)$ & $(166.149,52)$ & $(79.440,50)$ & $(45.979,77)$ & $(0,0937)$ & $(0,1563)$ & $(0,1205)$ \\
\hline \multicolumn{9}{|c|}{ PANEL D. Ecuación cuadrática (7) de pendiente diferente } \\
\hline$(-10,10)$ & $-0,0517$ & $-0,0935$ & $-51846,46$ & $-47.245,06$ & $-22.923,89$ & $-0,0005$ & $-0,1264$ & $-0,0203$ \\
\hline $\mathrm{n}=1.553$ & $(0,0674)$ & $(0,0688)$ & $(85.403,41)$ & $(41.896,40)$ & $(26.408,99)$ & $(0,0536)$ & $(0,0816)$ & $(0,0638)$ \\
\hline$(-5,5)$ & $-0,0276$ & $-0,0527$ & $74.834,48$ & $13.802,81$ & $-8.175,36$ & 0,0786 & $-0,0076$ & $-0,0169$ \\
\hline $\mathrm{n}=884$ & $(0,1123)$ & $(0,1148)$ & $(140.507,16)$ & $(69.699,86)$ & $(44.858,12)$ & $(0,0891)$ & $(0,1304)$ & $(0,1075)$ \\
\hline$(-4,4)$ & 0,1317 & 0,1501 & $108.754,10$ & $90.357,55$ & $-25.437,09$ & 0,1470 & 0,0674 & $0,2509^{*}$ \\
\hline $\mathrm{n}=741$ & $(0,1481)$ & $(0,1516)$ & $(190.872,24)$ & $(92.479,90)$ & $(55.866,04)$ & $(0,1183)$ & $(0,1729)$ & $(0,1453)$ \\
\hline$(-3,3)$ & $-0,1471$ & $-0,0346$ & $-5.7623,07$ & $-47.966,26$ & $-142.963,98^{*}$ & $-0,1008$ & 0,1700 & 0,2521 \\
\hline $\mathrm{n}=623$ & $(0,2452)$ & $(0,2529)$ & $(322.254,64)$ & $(159.169,70)$ & $(79.829,47)$ & $(0,1869)$ & $(0,3168)$ & $(0,2548)$ \\
\hline$(-2,2)$ & $-0,0843$ & $-0,0509$ & $56.594,79$ & $12.547,07$ & $-57.356,28$ & 0,0526 & $-0,1125$ & $0,2557^{* *}$ \\
\hline $\mathrm{n}=447$ & $(0,1257)$ & $(0,1302)$ & $(151.172,67)$ & $(71.992,39)$ & $(54.787,13)$ & $(0,1001)$ & $(0,1692)$ & $(0,1182)$ \\
\hline
\end{tabular}

Notas: ${ }^{*},{ }^{* *} \mathrm{y}{ }^{* *}$ corresponden a un nivel de significancia del $10 \%, 5 \%$ y $1 \%$ respectivamente.

El dato entre paréntesis debajo del coeficiente del efecto es la desviación estándar robusta.

Fuente: elaboración de los autores con base en la información de inscritos y Sisbén 2015.

de considerar también los casos en los cuales no se migra a una zona de menor estratificación. Si bien no se muestran los resultados, los coeficientes en este caso tienen el signo positivo, pero no hay significancia estadística.

Ahora, con la intención de verificar si la población no elegible al programa en el margen tuvo acceso a la educación superior, a pesar de no ser seleccionada -debido al uso de otras fuentes de financiación, por ejemplo-, se hizo una regresión en la que se controla por las mismas variables de las cuatro ecuaciones iniciales, pero se adiciona una dummy que toma el valor de 1 si el inscrito tiene como último nivel educativo alcanzado (según fuente de Sisbén 2015) una carrera técnica profesional, tecnológica, universitaria o posgrado; y o, en otro caso.
Los resultados se sintetizan en la Tabla 6 para los seis anchos de banda y se identifica el efecto para inscritos hasta el 2010:II, y para el total.

De acuerdo con los resultados, se observa un efecto positivo significativo cuando se considera el total de la población con un porcentaje entre el $6 \%$ y el $12 \%$. Esto indica que los beneficiarios tienen mayores posibilidades de acceder al estudio gracias a PLyPP. Sin embargo, es de recalcar que Medellín cuenta con un alto número de opciones para financiamiento de estudios superiores a través de los fondos de Sapiencia, crédito del ICETEX, créditos y becas directas con las IES y los programas nacionales de financiamiento como el Programa Ser Pilo Paga. La realidad de Medellín es que es una de las ciudades del país (junto con Manizales y 
Silvio Fernando López-Mera • David Eduardo Quintero-Rendón

\begin{tabular}{|c|c|c|c|c|c|c|c|c|c|c|c|}
\hline \multirow{2}{*}{ Ecuación } & \multicolumn{5}{|c|}{ Hasta 2010:II } & \multicolumn{6}{|c|}{ Hasta 2015:I } \\
\hline & $(-10,10)$ & $(-5,5)$ & $(-4,4)$ & $(-3,3)$ & $(-2,2)$ & $(-10,10)$ & $(-5,5)$ & $(-4,4)$ & $(-3,3)$ & $(-2,2)$ & $(-1,1)$ \\
\hline \multirow{2}{*}{$\begin{array}{c}\text { Ecuación } \\
\text { (3) }\end{array}$} & 0,0432 & 0 , & 0 & & & ** & * & $*$ & $*$ & $* *$ & 0,0072 \\
\hline & $(0,0471)$ & $(0,0633)$ & $(0,0690)$ & $(0,0751)$ & $(0,0905)$ & $(0,0226)$ & $(0,0298)$ & $(0,0328)$ & $(0,0368)$ & $(0,0436)$ & $(0,0573)$ \\
\hline \multirow{2}{*}{$\begin{array}{c}\text { Ecuación } \\
\text { (5) }\end{array}$} & 0,05 & 0,05 & 0 , & 0 & 0,14 & 0,06 & 0,0 & $*$ & 0,0 & 0,06 & \\
\hline & $(0,0482)$ & $(0,0663)$ & $(0,0754)$ & $(0,0849)$ & $(0,1128)$ & $(0,0227)$ & $(0,0307)$ & $(0,0345)$ & $(0,0399)$ & $(0,0529)$ & \\
\hline \multirow{2}{*}{$\begin{array}{c}\text { Ecuación } \\
\text { (6) }\end{array}$} & 0 , & 0, & 0 , & OC & 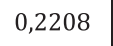 & $0,069^{*}$ & $0,0655^{* *}$ & $0,097^{* * *}$ & 0,098 & 0,0 & 0,0072 \\
\hline & $(0,0493)$ & $(0,0699)$ & $(0,0816)$ & $(0,0939)$ & $(0,1378)$ & $(0,0229)$ & $(0,0322)$ & $(0,0369)$ & $(0,0440)$ & $(0,0636)$ & $(0,0573)$ \\
\hline \multirow{2}{*}{$\begin{array}{l}\text { Ecuación } \\
\text { (7) }\end{array}$} & 0,0097 & 0,1171 & 0,1038 & 0,4260 & $-0,0107$ & $0,0705^{* *}$ & $0,1297^{* *}$ & 0,0775 & 0,055 & $-0,0170$ & \\
\hline & $(0,0767)$ & $(0,1273)$ & $(0,1669)$ & $(0,2701)$ & $(0,1395)$ & $(0,0350)$ & $(0,0589)$ & $(0,0760)$ & $(0,1200)$ & $(0,0670)$ & \\
\hline
\end{tabular}

Fuente: elaboración de los autores con información de inscritos y Sisbén 2015.

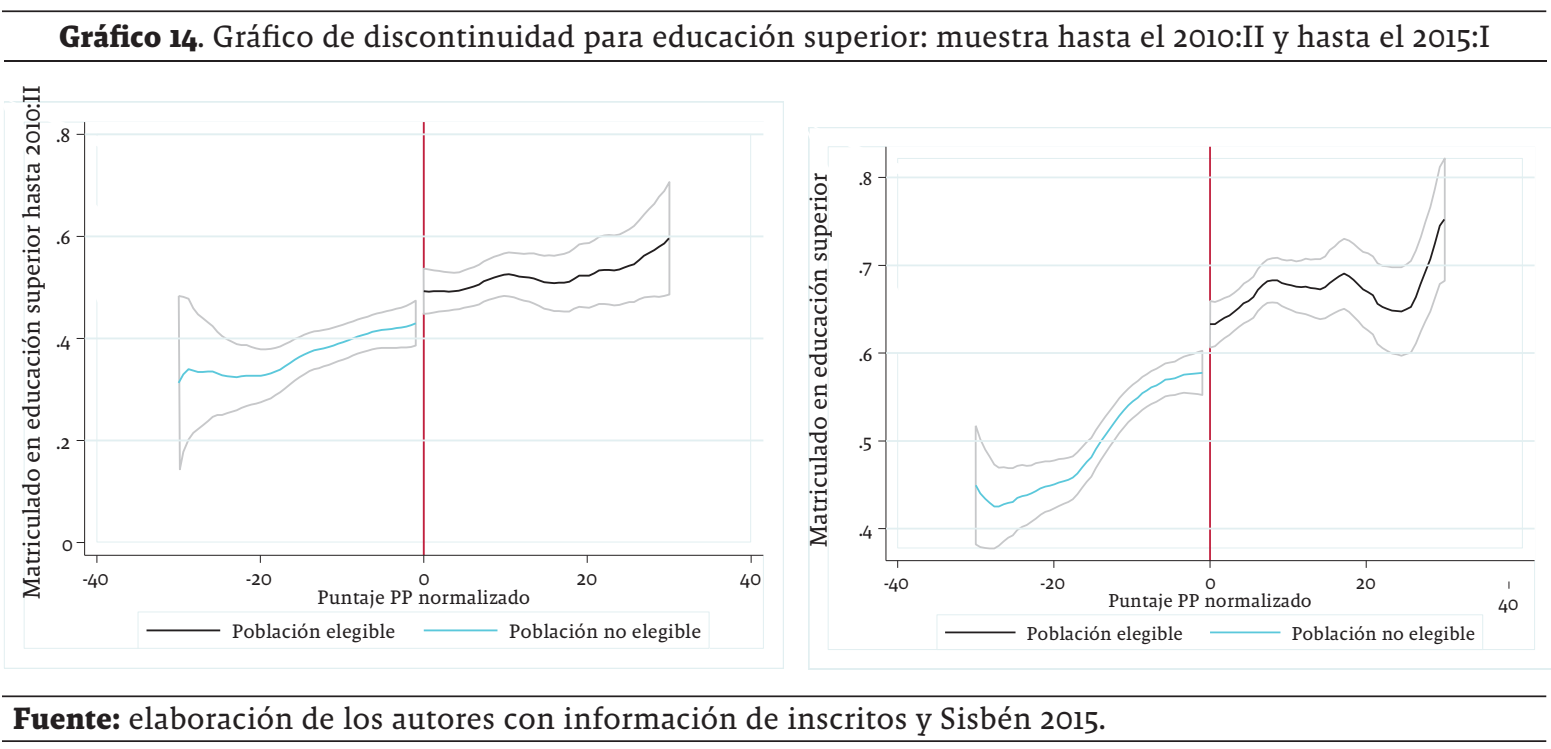

Bucaramanga) con mayores oportunidades de acceso y permanencia a la educación superior (Portafolio, 2017). En el Gráfico 14, se muestra la discontinuidad para las dos muestras, evidenciándola en este outcome.

\section{Discusión y recomendaciones de política}

Se hace un llamado a las administraciones a que incluyan dentro de su gestión el componente de evaluaciones, con el fin de identificar si ha sido o no exitosa y aprender de ella.

$\mathrm{Al}$ respecto, se extiende un llamado al MEN, a la
Alcaldía y a los investigadores a hacer visibles los resultados que han tenido este tipo de programas. Y esto es más necesario si dichas acciones involucran un destino importante del erario. Un manual de la evaluación de resultados considerablemente útil es el modelo propuesto por Kusek y Rist (2005).

Frente a los resultados hallados con la metodología de RDD, es preciso mencionar que con ella se estarían analizando individuos muy parecidos (alrededor del puntaje de corte) y, por la misma naturaleza del análisis, podría argüirse que los inscritos son personas hábiles y motivadas, y que, al no quedar 
elegidas en PLyPP, encuentran posiblemente otras fuentes de financiación que los lleva a comportarse de manera similar.

Se encontraron resultados negativos de PLyPP en la probabilidad de ocuparse, en la percepción de ingresos y su monto, y positivos en el embarazo, al reducirse su probabilidad. Así que el programa estaría reduciendo, en el corto plazo, las posibilidades de empleo y de ingresos de los beneficiarios en el margen. $Y$ estaría reduciendo también la ocurrencia de embarazo.

Para complementar los resultados de esta investigación, es posible estimar el efecto usando alguna metodología de matching. Adicionalmente, se podría buscar una base más actualizada del Sisbén, con el fin de identificar algún efecto de largo plazo adicional. Queda también, en el abanico, preguntarse: ¿son suficientes los auxilios económicos que da el programa?

Como otro ejercicio, se podría hacer el intento de identificar efectos positivos (reducción) en crimen (como en Ospina y Gimenez, 2009), en embarazo adolescente o en matrimonios prematuros (Cañada, 2011), por ejemplo.

Es importante también mejorar los sistemas de orientación vocacional y laboral en las instituciones de educación media. De tal manera que el estudiante que se encuentre próximo a tomar la elección de la Institución de Educación Superior y el programa, en donde estudiará, cuente con la información suficiente para decidir.

Otro reto importante, para los hacedores de política, es trabajar por mantener un robusto sistema de seguimiento a los bachilleres y a los graduados de estudios superiores, que permita conocer y caracterizar a la población que está dentro del sistema educativo, y hacer un monitoreo de la deserción/permanencia. También conviene estudiar las mejores formas de financiación, y preguntarse si es mejor financiar la oferta o subsidiar a la demanda.
Otra preocupación relacionada con lo anterior, y a la que el gobierno debe prestar atención, es que el presupuesto estatal para la educación superior pública no ha mostrado ningún cambio significativo en relación al PIB. Esto sugiere que el papel del Estado se ha visto disminuido y no ha sabido responder de forma adecuada -y rápida- al acelerado crecimiento de la demanda de los jóvenes en el acceso a los cupos de educación superior (Melo, Ramos y Hernández, 2014).

También conviene preguntarse si la política integral de educación debería atender a los que no son tan "pilos" y a los que no son tan "pobres", a través de un modelo más equitativo y eficaz de financiación de la oferta pública.

De igual manera, hay que señalar la necesidad de determinar a quién le está llegando el programa, esto es, la focalización, con el fin de determinar si debe o no continuar con el mismo mecanismo de elegibilidad.

\section{Conclusiones}

Se encontró evidencia suficiente de un efecto local de corto plazo del programa en el mercado laboral: en el margen, los beneficiarios tienen menor probabilidad de ocuparse y, por lo tanto, de devengar ingresos. Esto porque, dentro de su jornada diaria, está la actividad académica que reduce o limita la alternativa de disponer tiempo en otras actividades como la laboral. No significa que PLyPP tenga un efecto negativo, sino que en el corto plazo reduce el logro (empleo y remuneración) en el mercado laboral, pero al esperar más tiempo sería posible encontrar efectos positivos en el mercado de trabajo para la población beneficiaria, tras mejorar su capital humano. Para ratificar lo anterior, se requerirá contar con información post-tratamiento en la que buena parte de los beneficiarios, que en su mayoría han elegido carreras universitarias (de 5 años), hayan culminado sus estudios.

De igual manera, se encontró un efecto positivo en la ocurrencia de embarazo: las mujeres elegibles ubicadas cerca al umbral presentan 
Silvio Fernando López-Mera • David Eduardo Quintero-Rendón

\section{Anexos}

\begin{tabular}{|c|c|c|}
\hline \multicolumn{3}{|c|}{ Anexo 1. Puntajes por ítem de interés } \\
\hline Variable & Criterio & Puntaje \\
\hline \multirow[t]{3}{*}{ Estrato } & Estrato l & 15 \\
\hline & Estrato 2 & 12 \\
\hline & Estrato 3 & 9 \\
\hline \multirow[t]{2}{*}{ Sector IES } & Pública & 10 \\
\hline & Privada & 5 \\
\hline \multirow[t]{4}{*}{ Resultado ICFES } & 320 puntos o Puesto $1-250$ & 30 \\
\hline & 270-319 puntos o $251-550$ & 20 \\
\hline & 220-269 puntos o Puesto $551-850$ & 12 \\
\hline & Inferior a 220 puntos o Puesto $851-1000$ & 9 \\
\hline \multirow[t]{2}{*}{ Modalidad del Programa } & Técnica Profesional-Tecnología & 10 \\
\hline & Profesional Universitario & 8 \\
\hline \multirow[t]{2}{*}{ Sector del Colegio que egresó } & Oficial-cobertura de Medellín & 15 \\
\hline & Privada u otras & 8 \\
\hline \multirow[t]{3}{*}{ Año de graduación } & Año anterior al de la convocatoria & 10 \\
\hline & Dos o más años anteriores a la convocatoria & 8 \\
\hline & Continuación formación técnica según educación media & 20 \\
\hline \multicolumn{3}{|c|}{ En caso de contar con recursos para atender a la población de estratos 4, 5 y 6 se adiciona: } \\
\hline \multirow{3}{*}{ Nivel Sisbén } & Entre o y 3 & 15 \\
\hline & Entre 406 & 10 \\
\hline & No tiene & 0 \\
\hline \multirow{5}{*}{ Puntaje Sisbén } & $0-39,32$ & 15 \\
\hline & $39,33-48,49$ & 10 \\
\hline & $48,50-56,73$ & 5 \\
\hline & $56,74-100$ & 3 \\
\hline & No tiene & 0 \\
\hline
\end{tabular}

Fuente: elaboración de los autores con información de Sapiencia.

\begin{tabular}{|c|c|c|c|c|c|c|c|c|}
\hline $\begin{array}{l}\text { Puntaje } \\
\text { alrededor del } \\
\text { corte }\end{array}$ & Hombre & $\begin{array}{c}\text { Edad al } \\
\text { momento } \\
\text { de la } \\
\text { inscripción }\end{array}$ & $\begin{array}{c}\text { Nacido } \\
\text { en } \\
\text { Medellín }\end{array}$ & $\begin{array}{c}\text { Jefatura } \\
\text { masculina } \\
\text { en el } \\
\text { hogar }\end{array}$ & $\begin{array}{c}\text { Tamaño } \\
\text { del hogar } \\
2015\end{array}$ & $\begin{array}{c}\text { Edad del jefe } \\
\text { del hogar al } \\
\text { momento de } \\
\text { la solicitud } \\
2015 \\
\end{array}$ & $\begin{array}{c}\text { Años de } \\
\text { diferencia } \\
\text { entre el } \\
\text { grado } 11 \text { y } \\
\text { solicitud }\end{array}$ & $\begin{array}{c}\text { Tenencia } \\
\text { de gas } \\
\text { domiciliario } \\
\text { en el hogar } \\
2015 \\
\end{array}$ \\
\hline$(-10,10)$ & 0,0038 & $-0,1973$ & $0,0363^{*}$ & 0,0123 & 0,1183 & $-0,1495$ & 0,3576 & $-0,0214$ \\
\hline Observaciones & 5.291 & 5.292 & 0.340 & 5.720 & 5.720 & 4.954 & 7.292 & 5.726 \\
\hline$(-5,5)$ & $-0,0000$ & $-0,6682^{*}$ & 0,0211 & 0,0330 & $0,3553^{* *}$ & 0,1797 & 0,4504 & 0,0051 \\
\hline Observaciones & 2.981 & 2.981 & 3.549 & 3.203 & 3.203 & 2.798 & 4.091 & 3.203 \\
\hline$(-4,4)$ & $-0,0101$ & $-0,4095$ & 0,0159 & 0,0315 & $0,4937^{* * *}$ & 0,3900 & 0,5836 & 0,0246 \\
\hline Observaciones & 2.415 & 2.415 & 2.892 & 2.617 & 2.617 & 2.284 & 3.352 & 2.617 \\
\hline$(-3,3)$ & $-0,0004$ & $-0,8041$ & 0,0196 & 0,0255 & $0,3500^{*}$ & 0,3825 & 0,2336 & $0,1129^{* *}$ \\
\hline Observaciones & 1.990 & 1.990 & 2.392 & 2.150 & 2.150 & 1.891 & 2.769 & 2.150 \\
\hline$(-2,2)$ & 0,0451 & $-0,2811$ & $-0,0286$ & 0,0530 & $0,7233^{* * *}$ & $-0,5820$ & 0,9292 & 0,0881 \\
\hline Observaciones & 1.511 & 1.511 & 1.813 & 1.605 & 1.605 & 1.423 & 2.087 & 1.606 \\
\hline$(-1,1)$ & $-0,0378$ & $-0,499$ & 0,0485 & $0,1773^{*}$ & 0,0932 & & 0,9405 & $0,1486^{*}$ \\
\hline Observaciones & 931 & 931 & 1.138 & 1.022 & 1.022 & & 1.320 & 1.022 \\
\hline
\end{tabular}

Nota: * ${ }^{* *}, \mathrm{y}^{* * *}$ corresponde a los niveles de significancia del $10 \%, 5 \%, 1 \%$, respectivamente.

Fuente: elaboración de los autores con información de la base de inscritos cruzada con Sisbén 2015. 


\begin{tabular}{|c|c|c|c|c|c|c|c|c|}
\hline \multicolumn{9}{|c|}{ Anexo 3. Pruebas de continuidad en las variables de control seleccionadas: Hasta 2010:II } \\
\hline $\begin{array}{c}\text { Puntaje } \\
\text { alrededor del } \\
\text { corte }\end{array}$ & Hombre & $\begin{array}{c}\text { Edad al } \\
\text { momento } \\
\text { de la } \\
\text { inscripción }\end{array}$ & $\begin{array}{c}\text { Nacido } \\
\text { en } \\
\text { Medellín }\end{array}$ & $\begin{array}{c}\text { Jefatura } \\
\text { masculina } \\
\text { en el hogar }\end{array}$ & $\begin{array}{c}\text { Tamaño } \\
\text { del hogar } \\
2015\end{array}$ & $\begin{array}{c}\text { Edad del jefe } \\
\text { del hogar al } \\
\text { momento de } \\
\text { la solicitud } \\
2015 \\
\end{array}$ & $\begin{array}{c}\text { Años de } \\
\text { diferencia } \\
\text { entre el } \\
\text { grado } 11 \text { y } \\
\text { solicitud } \\
\end{array}$ & $\begin{array}{c}\text { Tenencia } \\
\text { de gas } \\
\text { domiciliario } \\
\text { en el hogar } \\
2015 \\
\end{array}$ \\
\hline$(-10,10)$ & 0,0259 & 1,578 & $-0,0451$ & $-0,0129$ & 0,0157 & $-0,6556$ & $1,0963^{* *}$ & $-0,0555$ \\
\hline Observaciones & 2.488 & 408 & 841 & 1.553 & 1.553 & 1.063 & 1.787 & 1.553 \\
\hline$(-5,5)$ & $-0,0159$ & 0,6916 & $-0,0043$ & 0,0005 & 0,3149 & 0,5102 & $1,3099^{*}$ & $-0,0228$ \\
\hline Observaciones & 1.400 & 247 & 486 & 884 & 884 & 612 & 1.031 & 884 \\
\hline$(-4,4)$ & 0,0043 & $-0,4093$ & $-0,0905$ & $-0,0184$ & 0,3833 & $-0,4488$ & $1,5225^{*}$ & 0,0063 \\
\hline Observaciones & 1.169 & 208 & 408 & 741 & 741 & 511 & 861 & 741 \\
\hline$(-3,3)$ & 0,0262 & 0,2018 & $-0,0251$ & 0,0044 & 0,4141 & $-0,5403$ & $1,6451^{*}$ & 0,0858 \\
\hline Observaciones & 969 & 173 & 349 & 623 & 623 & 444 & 726 & 623 \\
\hline$(-2,2)$ & 0,0822 & $-4,9350^{*}$ & 0,0058 & $-0,1065$ & 0,9161 & 0,5938 & 1,721 & $-0,0175$ \\
\hline Observaciones & 705 & 128 & 265 & 447 & 447 & 328 & 539 & 447 \\
\hline$(-1,1)$ & $-0,0790$ & $-0,3886$ & $-0,1858$ & & & & & \\
\hline Observaciones & 470 & 87 & 187 & & & & & \\
\hline
\end{tabular}

Fuente: elaboración de los autores con base en la información de inscritos y Sisbén 2015.

Anexo 4. Gráficos de discontinuidad para la identificación del efecto de PLyPP: Inscritos hasta el 2010:II
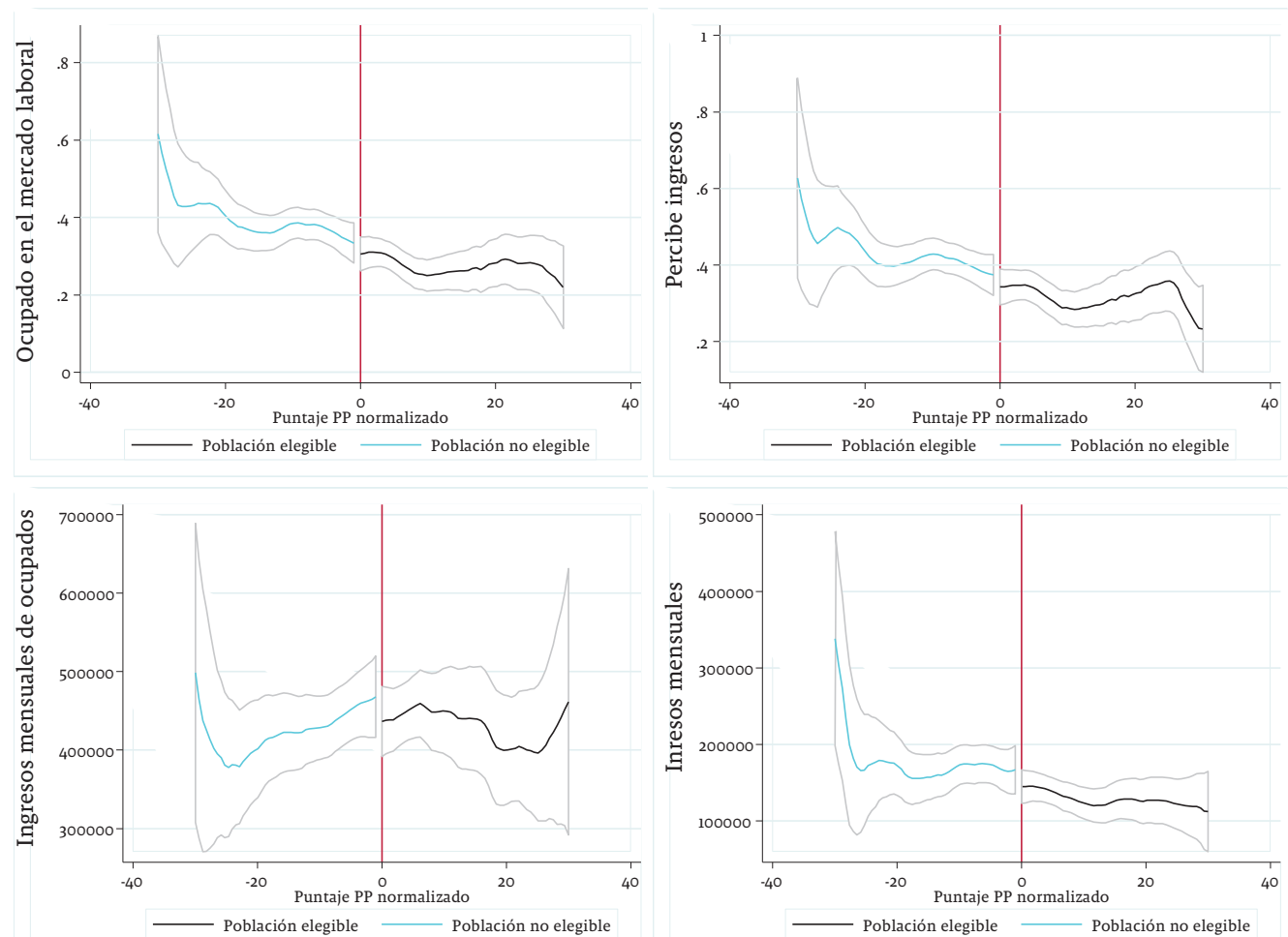
Silvio Fernando López-Mera • David Eduardo Quintero-Rendón
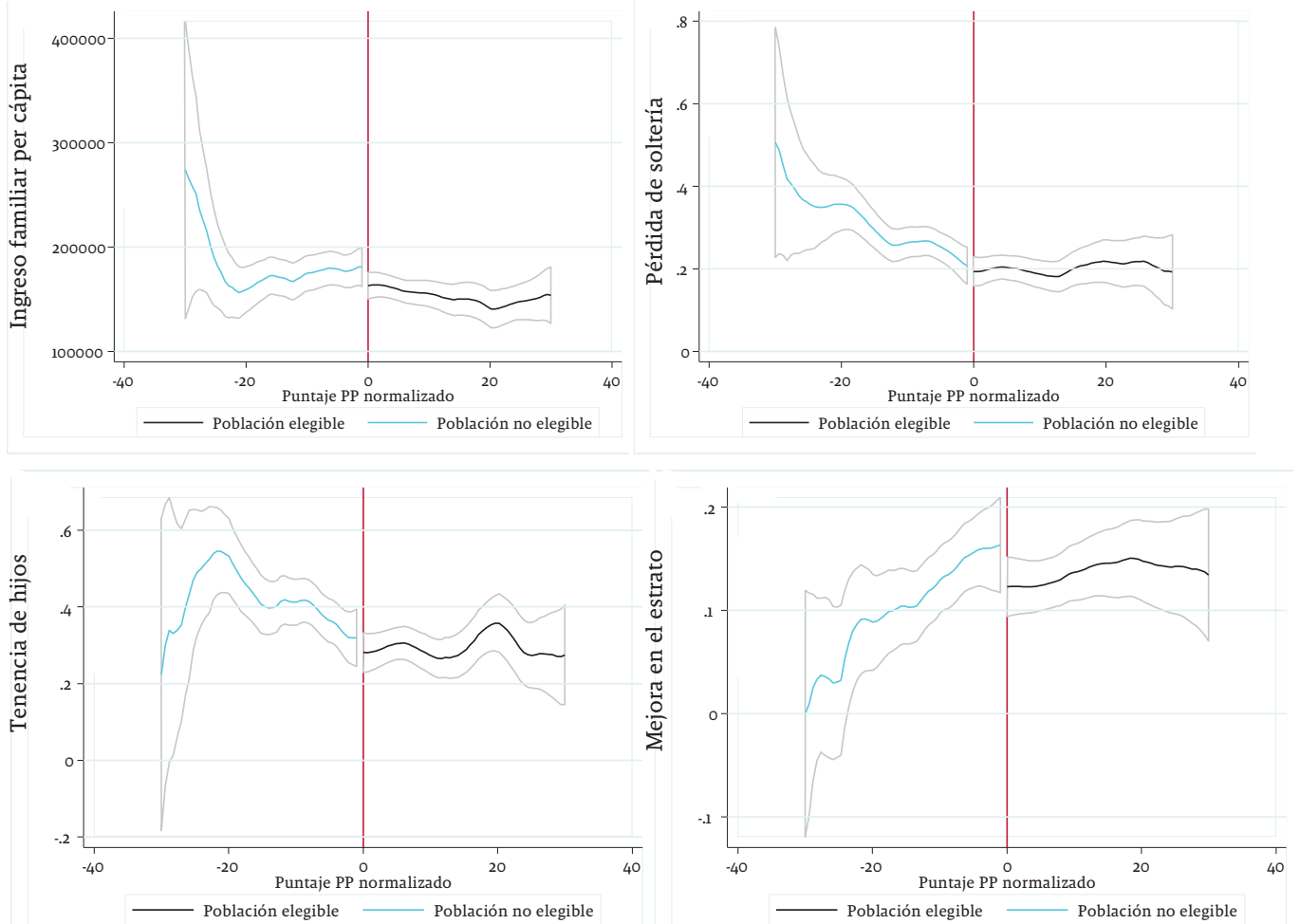

Fuente: elaboración de los autores con información de la base de inscritos cruzada con Sisbén 2015. 
una menor probabilidad de tener hijos. Así mismo, los elegibles parecen tener más probabilidad de mejorar su estrato socioeconómico y de acceder al sistema educativo superior. No se encontró evidencia con respecto a la pérdida de soltería.

\section{Referencias}

Acosta, J., Osorno, M. y Rodríguez, O. (2016). Subempleo y ocupación de los jóvenes y ciclo económico: la importancia del nivel educativo y la especialidad. Investigación de Economía de la educación, $11,699-717$.

Aguirre, M. (2010). Participación Ciudadana en la gestión pública local. El caso del presupuesto participativo de Medellín. Medellín, Colombia: s.e.

Cañada, J. (2011). Demografía y educación: Acceso al matrimonio y al mercado de trabajo en España 1980-2010. Revista Investigaciones en Economía de la Educación, 6, 835-866.

Correa, M. (2005). La feminización de la educación superior y las implicaciones en el mercado laboral y los centros de decisión política (tesis doctoral). Universidad Externado de Colombia, Bogotá, Colombia.

Dynarski, S. (2000). Hope for Whom? Financial Aid for the Middle Class and Its Impact on College Attendance. National Tax Journal, 53(3), 629-662.

Freire, O., Oliveira, C. y Teijeiro, M. (2016). The young self-employed tertiary graduates in Europe. Revista Investigaciones en Economía de la Educación, 11, 719-731.

Imbens, G. y Angrist, J. (1994). Identification and estimation of local average treatment effects. Econometrica, 62(2), 467-75.

Iriondo, I. (2016). Evaluación del impacto de la movilidad Erasmus en los salarios y el empleo de los recién graduados. Investigaciones en Economía de la Educación, 11, 753-769.

Kusek, J. y Rist, R. (2005). 10 pasos hacia un sistema de seguimiento y evaluación basado en resultados: Manual para gestores del desarrollo. Washington, US: Banco Mundial.

Lee, D. (2008). Randomized Experiments from Non-Random Selection in U.S. House Elections. Journal of Econometrics, 142(2), 675-697.

Lee, D. y Lemieux, T. (2010). Regression Discontinuity Designs in Economics. Journal of Economic Literature, 48(2), 281-355.

Lemieux, T. y Milligan, K. (2004). Incentive effects of social assistance: a regression discontinuity approach. Journal of Econometrics, 142(2), 807-828.

López, K. (2013). Evaluación de impacto del programa de becas y créditos sobre el acceso a la Educación Superior en Chile (tesis de maestría). Universidad de Chile, Santiago, Chile.

López, S. (2010). Aspectos determinantes de la calidad de la educación pública en Medellín: un análisis de los incentivos docentes. Ensayos de Economía, 20(37), 169-199. 
Martínez, P. (2016). Impacto de la Universidad en la sociedad: Un análisis desde la financiación de la educación superior en Colombia. Saber, Ciencia y Libertad, 12(1), 177-191.

Melo, L., Ramos, J. y Hernández, P. (2014). La educación superior en Colombia: Situación actual y análisis de eficiencia. Desarrollo y sociedad, (78), 59-111.

Monteiro, S., Almeida, L. y García, A. (2014). Towards a new understanding of the role of higher education: Factors impacting the employability of Portuguese graduates. Investigación de Economía de la educación, 9, 769-795.

Ospina, N. y Giménez, G. (2009). Violencia y actividad económica. Un análisis de los efectos sobre la educación en Latinoamérica. Investigaciones de Economía de la Educación, 4, 575-581.

Pantoja, F. (2010). Rentabilidad de la inversión en educación beneficios privados y sociales. Revista Gestión y Desarrollo, 7(2), 49-62.

Peña, X. y Bernal, R. (2011). Guía Práctica para la Evaluación de Impacto. Bogotá, Colombia: Universidad de Los Andes.

Pomeranz, D. (2011). Métodos de Evaluación, agosto. Recuperado de https://www.hbs.edu/faculty/ Supplemental\%20Files/Metodos-de-Evaluacion-de-Impacto_50067.pdf

Portafolio. (2017). Manizales, Bucaramanga y Medellín, las ciudades con mejores condiciones para los universitarios. Recuperado de http://www.portafolio.co/tendencias/ las-ciudades-con-mejores-condiciones-para-los-universitarios-503620

Sánchez, F. y Velasco, T. (2014). ¿Los préstamos para la educación superior mejoran el salario? Crédito Educativo y Mercado Laboral: Una aproximación de regresión discontinua para Colombia. Investigaciones en economía de la educación, 9, 769-795.

Sapiencia. (2017). Análisis diagnóstico de la educación y las políticas de educación superior en Medellín. Recuperado de http://www.sapiencia.gov.co/wp-content/uploads/2017/02/BRIEF-POLICYEDUCACI\%C3\%93N-SUPERIOR_-Versi\%C3\%B3n-2.pdf

Secretaría de Educación de Medellín. (2017). Estudio de seguimiento a los bachilleres de instituciones oficiales y de cobertura egresados en 2015: Año 2017. Informe. Medellín, Colombia: SEM.

Sen, A. (1999). Development as Freedom. Oxford/New York, UK/US: Oxford University Press/Alfred Knopf.

Solís, A. (2011). Credit Access and College Enrollment. Technical report. California, US: Department of Agricultural and Resource Economics, University of California. 